\title{
Current status of NADPH oxidase research in cardiovascular pharmacology
}

This article was published in the following Dove Press journal:

Vascular Health and Risk Management

24 July 2013

Number of times this article has been viewed

\author{
Bruno K Rodiño-Janeiro',2 \\ Beatriz Paradela-Dobarro' \\ María Isabel Castiñeiras- \\ Landeira' \\ Sergio Raposeiras-Roubín ${ }^{1,3}$ \\ José R González- \\ Juanatey ${ }^{1,3,4}$ \\ Ezequiel Álvarez ${ }^{1,4}$
}

'Health Research Institute of Santiago de Compostela, Santiago de Compostela, Spain; ${ }^{2}$ European Molecular Biology Laboratory, Grenoble, France; ${ }^{3}$ Cardiology Department, University Clinic Hospital of Santiago de Compostela, Santiago de Compostela, Spain; ${ }^{4}$ Medicine Department, University of Santiago de Compostela, Santiago de Compostela, Spain
Correspondence: Ezequiel Álvarez Laboratory 6, Health Research Institute of Santiago de Compostela, University Clinic Hospital of Santiago de Compostela,

Travesía de la Choupana s/n, 15706

Santiago de Compostela, Spain

Tel +34 98I 955074

Email ezequiel.alvarez@usc.es

\begin{abstract}
The implications of reactive oxygen species in cardiovascular disease have been known for some decades. Rationally, therapeutic antioxidant strategies combating oxidative stress have been developed, but the results of clinical trials have not been as good as expected. Therefore, to move forward in the design of new therapeutic strategies for cardiovascular disease based on prevention of production of reactive oxygen species, steps must be taken on two fronts, ie, comprehension of reduction-oxidation signaling pathways and the pathophysiologic roles of reactive oxygen species, and development of new, less toxic, and more selective nicotinamide adenine dinucleotide phosphate (NADPH) oxidase inhibitors, to clarify both the role of each NADPH oxidase isoform and their utility in clinical practice. In this review, we analyze the value of NADPH oxidase as a therapeutic target for cardiovascular disease and the old and new pharmacologic agents or strategies to prevent NADPH oxidase activity. Some inhibitors and different direct or indirect approaches are available. Regarding direct NADPH oxidase inhibition, the specificity of NADPH oxidase is the focus of current investigations, whereas the chemical structure-activity relationship studies of known inhibitors have provided pharmacophore models with which to search for new molecules. From a general point of view, small-molecule inhibitors are preferred because of their hydrosolubility and oral bioavailability. However, other possibilities are not closed, with peptide inhibitors or monoclonal antibodies against NADPH oxidase isoforms continuing to be under investigation as well as the ongoing search for naturally occurring compounds. Likewise, some different approaches include inhibition of assembly of the NADPH oxidase complex, subcellular translocation, post-transductional modifications, calcium entry/release, electron transfer, and genetic expression. High-throughput screens for any of these activities could provide new inhibitors. All this knowledge and the research presently underway will likely result in development of new drugs for inhibition of NADPH oxidase and application of therapeutic approaches based on their action, for the treatment of cardiovascular disease in the next few years.
\end{abstract}

Keywords: nicotinamide adenine dinucleotide phosphate oxidase, NOX, cardiovascular therapeutic targets, inhibitors, pharmacophore models

\section{Introduction}

The implications of reactive oxygen species (ROS) in cardiovascular disease have been known for some decades. Rationally, therapeutic antioxidant strategies combating oxidative stress have been developed, but the results of clinical trials have not been as good as expected. ${ }^{1}$ There is no convincing explanation for that, but we know now that ROS not only have pathologic effects but also, in the appropriate subcellular compartments and under proper antioxidant control, participate in signaling pathways that are crucial for cellular functioning. Therefore, blocking production of ROS should submit your manuscript | www.dovepress.con

Dovepress

http://dx.doi.org// 0.2/47/VHRM.S33053 
be selective and appropriate to have therapeutic activity. Pathways sensitive to oxidation/reduction are known by the generic name of "redox signaling" pathways. However, the participation of different ROS, the existence of different sources of ROS in the same cell, and the complex relationship between different signaling routes draw a complex picture and we do not have the necessary global view for this kind of cellular signaling. Our knowledge of the way in which ROS participate in pathophysiologic processes is also limited, in part by the absence of appropriately sensitive and selective probes for ROS and in part by having nonspecific pharmacologic tools for inhibition of production of ROS. This explains why we do not have well defined therapeutic targets for preventing the action of ROS in cardiovascular disease. In this sense, evidence has been accumulating regarding the important role of nicotinamide adenine dinucleotide phosphate (NADPH) oxidase in generation of ROS in the cardiovascular system. This membrane enzyme complex is defined mainly by its catalytic subunit, which has seven different isoforms. The characteristics and roles of this enzyme make it a suitable candidate for a good therapeutic target. However, further investigations are needed into the different roles of the NADPH oxidase isoforms and their participation in signaling pathways, in addition to the requirement for developing isoform-specific inhibitors. Therefore, to move forward in the design of new therapeutic strategies for cardiovascular disease based on prevention of ROS production, steps must be taken on both fronts, ie, comprehension of reduction-oxidation (redox) signaling pathways and the pathophysiologic roles of ROS, and the development of new, less toxic and more selective NADPH oxidase inhibitors, allowing clarification of the role of each NADPH oxidase isoform and its potential use in clinical practice. In this review, we assess the value of NADPH oxidase as a therapeutic target in cardiovascular disease as well as old and new pharmacologic agents and strategies to prevent the activity of NADPH oxidase.

\section{Targeting NADPH oxidase Oxidative stress: harmful or key signaling pathways}

The pathologic effects of ROS in the cardiovascular system result simultaneously from their direct actions modifying vascular cell functions and from their ability to scavenge and remove several beneficial vasoprotective compounds, such as nitric oxide. ROS have direct effects on vascular cells, including endothelial cells, vascular smooth muscle cells, fibroblasts, and even resident macrophages, which are also important in the early stages of cardiovascular disease. ${ }^{2}$ This includes the direct vasoregulatory effects of individual ROS, while others are regulated via toxic oxidation of proteins, lipids, and DNA. ${ }^{3}$ Overproduction of ROS activates prooxidative genes, such as hypoxia inducible factor- $1 \alpha$, leading to angiogenesis and cell proliferation, ${ }^{4}$ as well as a number of proinflammatory genes.

The interaction between nitric oxide and superoxide anions occurs so rapidly that it is impossible for the former molecule to have any biological effects. Therefore, many studies in cell cultures, animal models, and human vessels have shown that oxidative stress, in particular production of superoxide anions, is the single most important mechanism for endothelial dysfunction, ${ }^{5}$ a situation wherein endothelial cells are unable to provide vasoprotective and functional agents for the vessel wall (Figure 1).

On the other hand, ROS also have a role in key signaling pathways that are important for proper cell functioning. Participation of ROS has been described in a number of processes, including: regulation of gene expression by modification of the activity of transcription factors ${ }^{6-8}$ controlling the expression of adhesion molecules in the endothelium ${ }^{9,10}$ or proteins implicated in cell proliferation and migration, ${ }^{11-14}$ regulation of cytoskeletal activity, ${ }^{15}$ and control of intracellular concentrations of second messengers like calcium. ${ }^{16}$ Further, the implication of each type of ROS in modulation of responses seems to vary according to the region and type of vascular cell. Therefore, the final effects of each reactive molecule can vary depending on the region of tissue involved. ${ }^{17}$ This complexity may partially explain why direct scavenging of ROS by antioxidant vitamins did not demonstrate clinical benefit in the majority of large trials. ${ }^{18}$ Therefore, antioxidant strategies must be carefully designed based on a strong understanding of how ROS are involved in each pathophysiologic process.

\section{Central role of NADPH oxidases in generation of oxidative stress}

The main sources of ROS include redox enzymes such as NADPH oxidase, xanthine oxidase, lipooxygenase, and cyclooxygenase. It is important to note that these sources are continuously interacting with each other. NADPH oxidases are a family of multisubunit enzyme complexes that are unique in being the only enzymes that have been identified with the primary function of generating superoxide and/or hydrogen peroxide. ROS are produced as intermediates in redox reactions, leading from $\mathrm{O}_{2}$ to $\mathrm{H}_{2} \mathrm{O}$. The major 


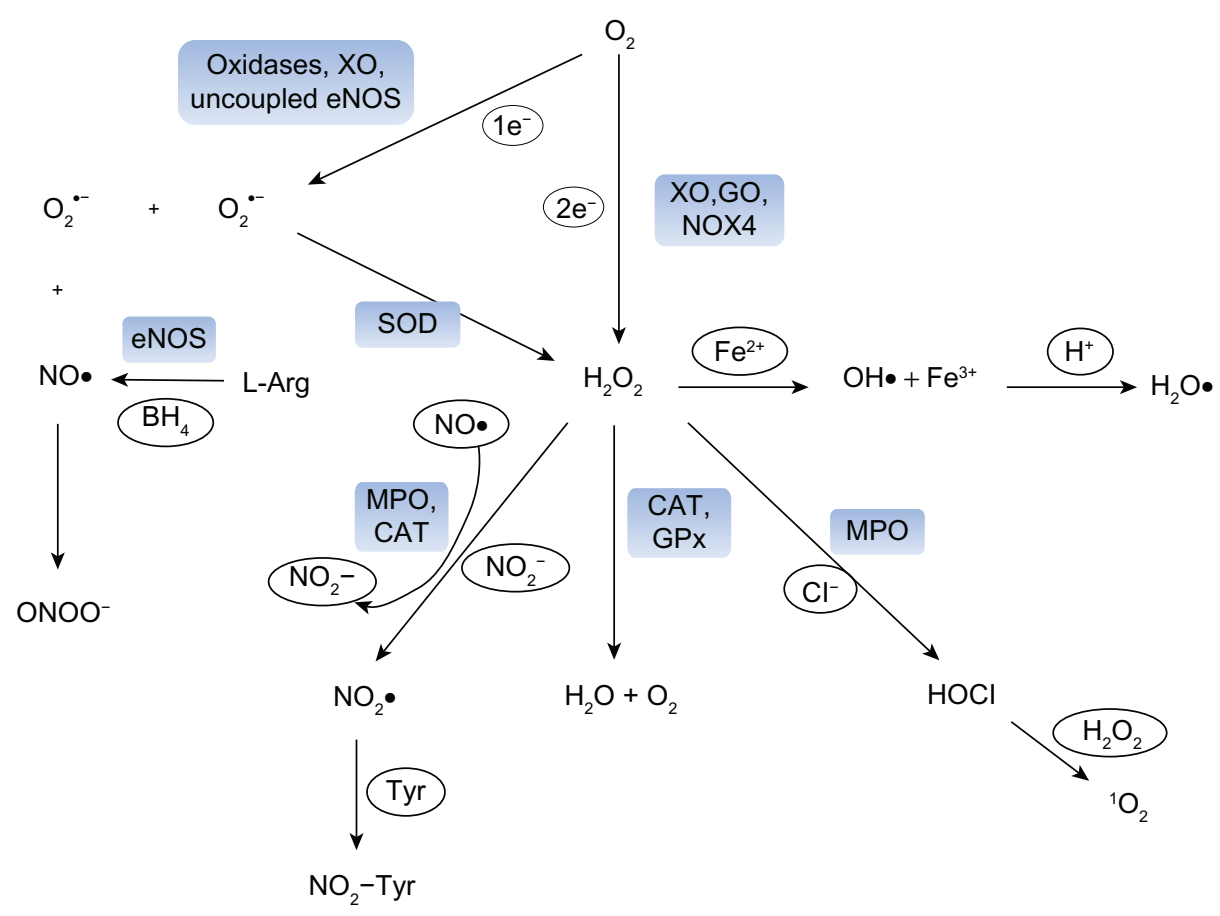

Figure I Formation of reactive oxygen species (ROS) in vascular cells. The reduction of oxygen $\left(\mathrm{O}_{2}\right)$ by one electron leads to the formation of superoxide anion $\left(\mathrm{O}_{2}{ }^{--}\right)$, which can be either dismutated to hydrogen peroxide $\left(\mathrm{H}_{2} \mathrm{O}_{2}\right)$ spontaneously or in a reaction catalyzed by superoxide dismutase (SOD). Nitric oxide (NO•) is produced by endothelial nitric oxide synthase (eNOS) from L-arginine ( $\mathrm{L}-\mathrm{Arg})$ and tetrahydrobiopterin. $\mathrm{O}_{2}^{-{ }^{-}}$and NO- react spontaneously with each other to form peroxynitrite $(\mathrm{ONOO}-) . \mathrm{H}_{2} \mathrm{O}_{2}$ can also be generated directly from oxygen by some vascular oxidases, such as xanthine oxidase (XO), glucose oxidase (GO) and $\mathrm{NOX} 4-\mathrm{containing}$ NADPH-oxidases (NOX4). $\mathrm{H}_{2} \mathrm{O}_{2}$ can be scavenged by catalase (CAT) or glutathione peroxidase (GPx) to form water and oxygen or can undergo non-enzymatic reactions to generate the hydroxyl radical $\left(\mathrm{OH}_{\bullet}\right)$ in the metal-catalyzed Haber-Weiss or Fenton reaction. $\mathrm{OH} \bullet$ may be protonated to the hydroperoxyl radical. Ferrous-containing enzymes, such as myeloperoxidase (MPO) are activated by $\mathrm{H}_{2} \mathrm{O}_{2}$ to form a highly reactive radical that can oxidize $\mathrm{NO} \cdot$ to nitrogen dioxide anion ( $\mathrm{NO}{ }_{2}^{-}$) and react with $\mathrm{NO}_{2}^{-}$to form nitrogen dioxide radical $\left(\mathrm{NO}_{2}{ }^{-}\right)$. $\mathrm{NO}_{2} \cdot$ can, in turn, participate in nitrating events, such as the formation of nitrotyrosines ( $\mathrm{NO}_{2}{ }^{-}$Tyr). Alternatively, $\mathrm{MPO}^{-}$can use $\mathrm{H}_{2} \mathrm{O}_{2}$ to form hypochlorous acid $(\mathrm{HOCl})$. Singlet oxygen $\left({ }^{\prime} \mathrm{O}_{2}\right)$ is formed upon the reaction of $\mathrm{HOCl}$ with $\mathrm{H}_{2} \mathrm{O}_{2}$.

Abbreviations: Ie- one electron; $2 \mathrm{e}^{-}$, two electrons; $\mathrm{BH}_{4}$, tetrahydrobiopterin; $\mathrm{Cl}^{-}$, chloride anion; $\mathrm{Fe}^{2+}$, ferrous iron; $\mathrm{H}^{+}$, hydrogen cation; $\mathrm{Tyr}$, tyrosine.

mechanism for generation of ROS begins with the reduction of $\mathrm{O}_{2}$, by the addition of one electron to generate a superoxide anion $\left(\mathrm{O}_{2}{ }^{--}\right)$, considered the primary ROS, and this is the reaction catalyzed by NADPH oxidases.

$\mathrm{O}_{2}^{\bullet-}$ interacts with other molecules to produce secondary ROS, directly or through enzyme-catalyzed or meta-catalyzed reactions. ${ }^{19}$ Reduction of $\mathrm{O}_{2}{ }^{\bullet-}$ leads to formation of $\mathrm{H}_{2} \mathrm{O}_{2}$, which is further converted to secondary metabolites, such as highly reactive hydroxyl $\mathrm{HO}^{\bullet}$. Although the favored reaction is generation of $\mathrm{H}_{2} \mathrm{O}_{2}, \mathrm{O}_{2}^{\bullet-}$ also reacts with nitric oxide $\left(\mathrm{NO}^{\bullet}\right)$ to form peroxinitrite $\left(\mathrm{ONOO}^{-}\right)$, with transition metals, such as iron found in iron/sulfur center-containing proteins, or it may be protonated to the hydroperoxyl radical $\left(\mathrm{H}_{2} \mathrm{O}^{\bullet}\right.$, Figure 1). $\mathrm{H}_{2} \mathrm{O}^{\bullet}$ is particularly important in lipid peroxidation and atherogenesis.

Seven isoforms of NADPH oxidase have been described in mammals. Each of these isoforms comprises a core catalytic subunit, ie, the so-called NADPH oxidase (NOX) and dual oxidase (DUOX) subunits, and up to five regulatory subunits. These regulatory subunits have important roles in: maturation and expression of the NOX and DUOX subunits in biological membranes, (ie, p22phox, DUOX activator 1, and DUOX activator 2), in enzyme activation (p67phox and NOX activator 1), and in spatial organization of the various components of the enzyme complex (p47phox, NOX organizer 1, and p40phox). ${ }^{20}$ Some NADPH oxidase isoforms also rely on the small guanine triphosphate hydrolases (GTPases), ie, RAC1 and RAC2, for their activation. Each NADPH oxidase isoform is defined by the nature of its catalytic subunit (NOX1-NOX5, DUOX1, or DUOX2), which determines its suit of regulatory subunits (Figure 2).

Although all NOX have the same function in generating ROS, mechanisms of activation, subunit requirements, and intracellular distributions vary between isoforms. Unlike phagocytic NADPH oxidases, which are activated only upon stimulation and generate $\mathrm{O}_{2}{ }^{--}$in a burst-like manner extracellularly, nonphagocytic NADPH oxidases are constitutively active, produce $\mathrm{O}_{2}{ }^{--}$intracellularly in a slow and sustained fashion, and act as intracellular signaling molecules, influencing not only transcription factors but also other molecules involved in inflammation, cell growth, 

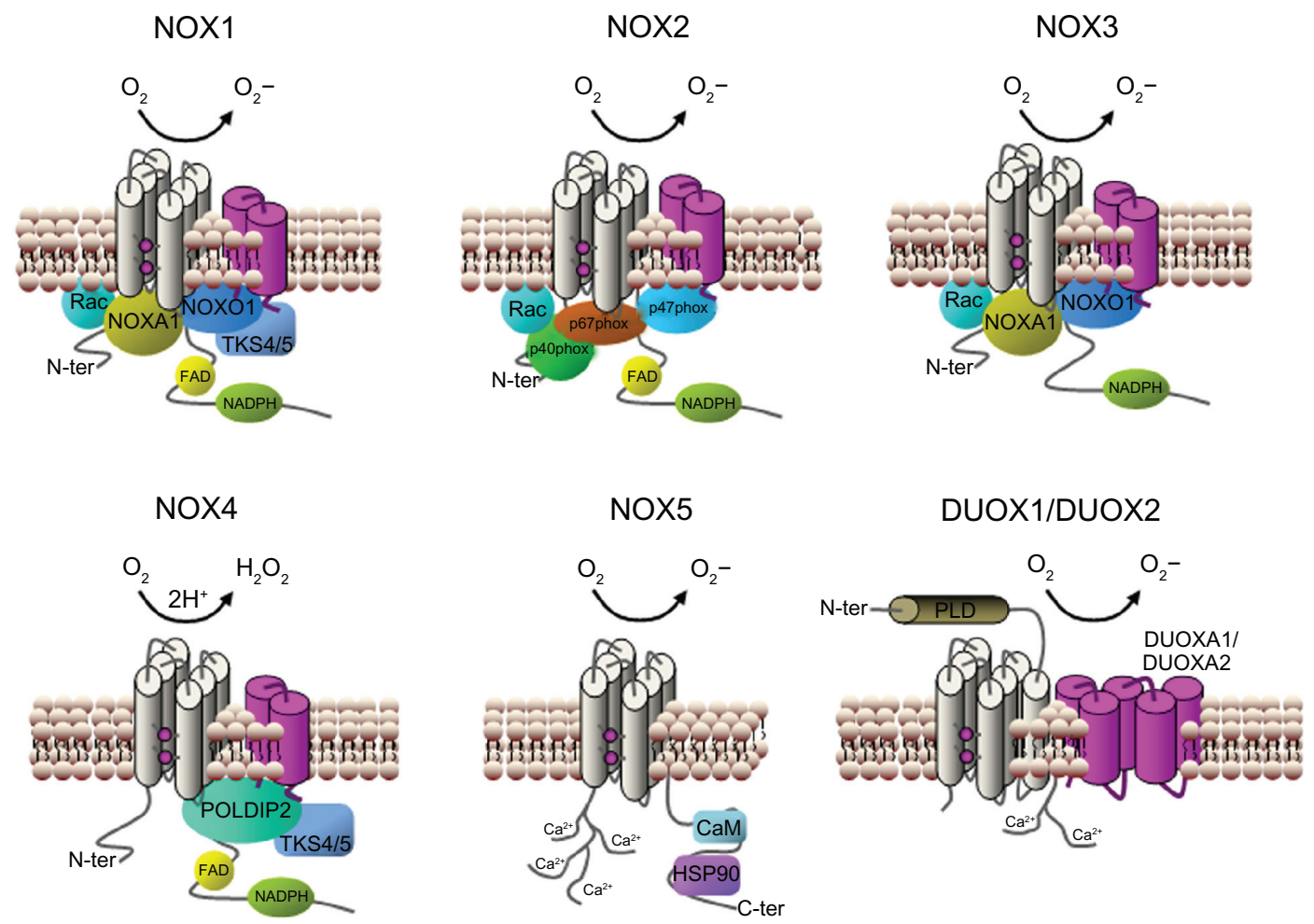

Figure 2 Subunit composition of the NADPH oxidase isoforms. The catalytic core subunits of the complex (NOXI-5 and DUOXI-2) are shown in grey and their stabilization partners (p22phox and DUOX activator I and 2) are shown in magenta. NOX4 is the only isoform that produces hydrogen peroxide instead of superoxide anion. The regulatory cytosolic subunits of each isoform are shown in each case: p40phox, p47phox, p67phox, NOX organizer I (NOXOI), NOX activator I (NOXAI), small GTPase (Rac), polymerase delta-interacting protein 2 (POLDIP2), a p47phox analog tyrosine kinase substrate with 4/5 SH3 domains (TKS4/5), EF hand motifs, (calciumbinding motifs composed of two helixes (E and F) joined by a loop), calmodulin (CaM) and heat shock protein 90 (HSP90). On DUXOI and DUOX2 a putative additional amino-terminal transmembrane domain and extracellular peroxidase-like region (PLD) are shown.

Abbreviations: C-ter, carboxy-terminal; FAD, flavin adenine dinucleotide; GTPase, guanine triphosphate hydrolase; NADPH, nicotinamide adenine dinucleotide phosphate; $\mathrm{N}$-ter, amino-terminal; $\mathrm{O}_{2}$, oxygen; $\mathrm{H}_{2} \mathrm{O}_{2}$, hydrogen peroxide; $\mathrm{O}_{2}-$, superoxide; $\mathrm{SH}$, Src-homology region 3.

and contraction, such as mitogen-activated protein kinases, tyrosine kinases, and protein phosphatases. ${ }^{21,22}$

ROS produced by NADPH oxidases have been shown to modify virtually all other possible sources of ROS (Figure 1). Changes in the structure of several oxidases caused by the overproduction of ROS from NADPH oxidases lead to their dysfunction and to a further increase in generation of ROS, forming a vicious cycle of oxidative stress. ${ }^{23} \mathrm{An}$ example is endothelial nitric oxide synthase, which primarily produces nitric oxide, but generates ROS rather than nitric oxide when it is uncoupled under pathologic conditions. Uncoupling of nitric oxide synthase occurs by oxidation of its cofactor tetrahydrobiopterin, and this oxidation depends on peroxynitrite, which is formed by reaction of nitric oxide with superoxide anions produced by NADPH oxidases. Similarly, production of superoxide anions by NADPH oxidase induces mitochondrial oxidative damage via structural changes to the inner mitochondrial membrane and disturbs flow in the electron transport chain, which enhances ROS production. ${ }^{24,25}$

\section{Validating the role of NADPH oxidase in cardiovascular health and disease}

NADPH oxidases are found in virtually every tissue and are the major source of superoxide anions observed in the vasculature. ${ }^{26}$ Multiple NOX oxidase isoforms are constitutively expressed in each of the predominant cell types of the vascular wall. Endothelial cells express NOX1, NOX2, NOX4, and NOX5; vascular smooth muscle cells express NOX1, NOX4, and NOX5; and adventitial fibroblasts express NOX2 and NOX4. ${ }^{19,27}$ In parallel with the two-way actions of ROS, NOX proteins have both beneficial and harmful effects. They are important signaling molecules that regulate vascular tone, expression, proliferation, migration, and differentiation. ${ }^{28}$ On the other hand, cardiovascular risk factors and vascular diseases increase ROS and contribute to atherosclerosis, vascular dysfunction, hypertension, vascular hypertrophy, and thrombosis. ${ }^{26,28}$ To inhibit NADPH oxidase successfully, it is important to understand these points (Figure 3). 


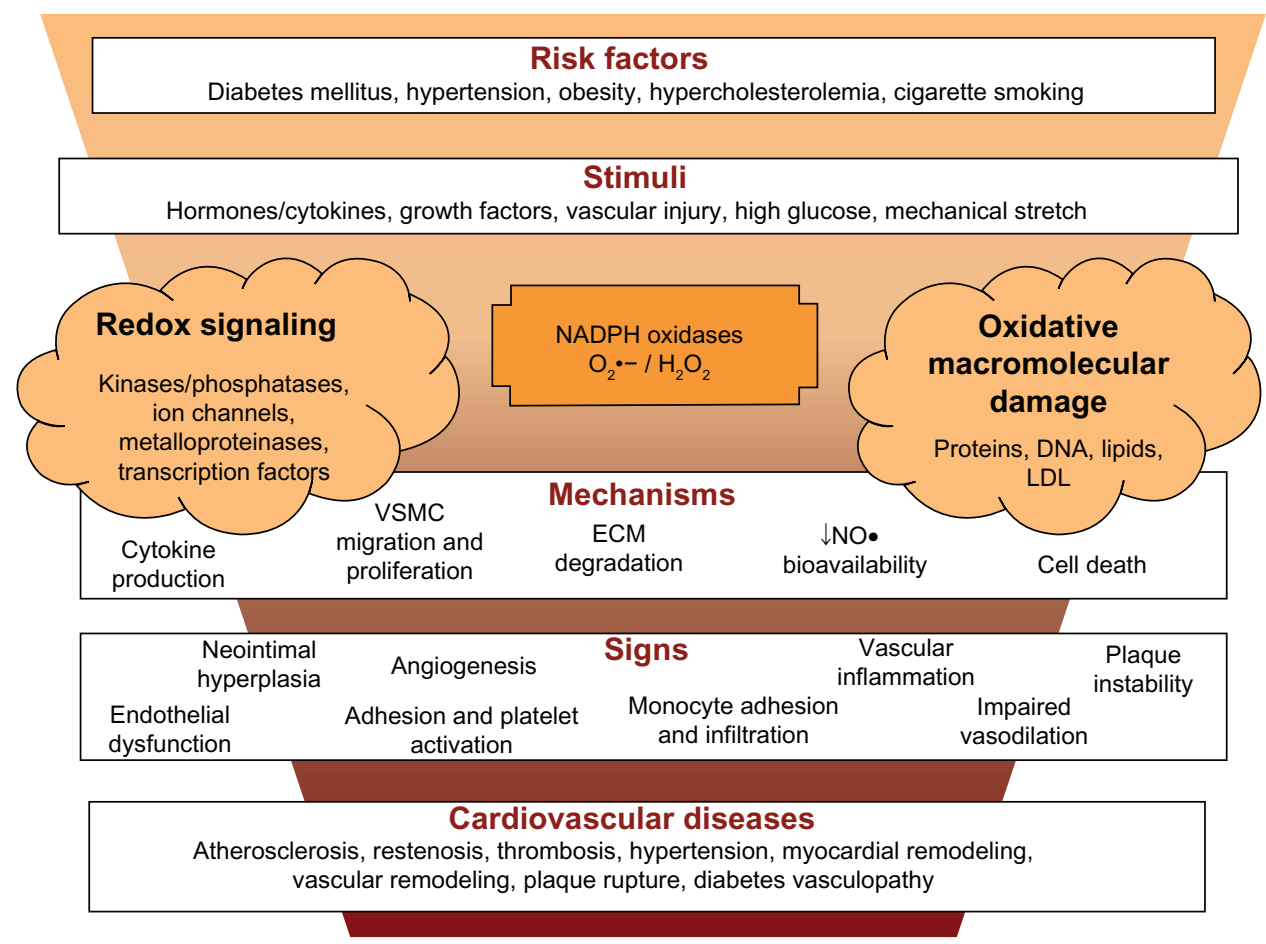

Figure 3 NADPH oxidase and cardiovascular diseases. Risk factors for cardiovascular diseases cause vascular injury and the release of cytokines and factors that activate NADPH oxidases. ROS generation (superoxide anion $\left(\mathrm{O}_{2}{ }^{--}\right)$and hydrogen peroxide $\left(\mathrm{H}_{2} \mathrm{O}_{2}\right)$ activate redox signaling, which trigger cellular responses or cause oxidative stress, which have the potential to originate oxidative macromolecular damage, decrease nitric oxide (NO•) bioavailability and increase oxidation of low-density lipoprotein (ox-LDL). All together contribute to vascular inflammation, dysfunction and platelet or leukocyte adhesion, which lead to multiple outcomes of cardiovascular disease.

Abbreviations: ECM, extra-cellular matrix; VSMC, vascular smooth muscle cells; NADPH, nicotinamide adenine dinucleotide phosphate; $\downarrow$, decrease; ROS, reactive oxygen species; LDL, low-density lipoprotein.

ROS are involved in a large number of cardiovascular diseases and the causal mechanisms are complex. Validating the involvement of a protein in a biological process requires experimental pharmacologic inhibition or genetic deletion and expressional confirmation studies (for a review, see Altenhofer et al). ${ }^{29}$ Vascular cells simultaneously express multiple NOX enzymes, and various cardiovascular diseases have been associated with changes in the expression of NOX1, NOX2, NOX4, and NOX5. In vascular smooth muscle cells from large arteries, NOX1 is required for migration, hypertrophy, and proliferation, NOX4 modulates differentiation, and NOX1 and NOX2 are implicated in hypertension. ${ }^{19}$

Expression of the vascular NOX2 subunit is commonly increased by proinflammatory stimuli or in the presence of cardiovascular risk factors. ${ }^{30}$ The endothelial injury and reduced nitric oxide signaling that occurs in the early stages of vascular disease is largely mediated by excessive levels of NOX2 oxidase-derived superoxide anion. ${ }^{17,30}$ Studies in transgenic and knockout animal models have shown the involvement of NOX1 and NOX2 and some of their regulatory subunits, such as $\mathrm{p} 47 \mathrm{phox}$, in the development of hypertension, atherosclerosis, and restenosis (for a review see Drummond et al). ${ }^{27}$ Therefore, there is a strong rationale for therapeutically targeting NADPH oxidases in the arterial wall for the treatment of vascular diseases.

\section{Vascular disease and atherosclerosis}

The demonstration that expression of the NOX1 and/or NOXA1 subunit is elevated in atherosclerotic lesions of apolipoprotein E-deficient $\left(A p o E^{-/-}\right)$mice and humans implies a role for the enzyme in this disease state. ${ }^{31,32}$ In support, there is evidence for a greater reduction in development of atherosclerotic lesions in the aortic arch of $\mathrm{NoxI}^{-1-} / \mathrm{ApoE}^{-/-}$double knockout mice compared with ApoE $E^{-/-}$single knockout mice. ${ }^{33} \mathrm{NOX} 2$ seems to participate in the redox signaling implicated in initiation and progression of atherosclerosis. Overexpression of NOX2 in $\mathrm{ApoE}^{-/-}$mice increased recruitment of macrophages, although did not alter progression of atherosclerosis. ${ }^{34}$

The case of NOX4 remains controversial. NOX4 is highly expressed in endothelial cells, vascular smooth muscle cells, and adventitial fibroblasts, and owing to its lack of reliance 
on traditional cytosolic organizer and activator subunits, NOX 4 activity was, until recently, ${ }^{35}$ thought to be regulated primarily by changes in expression of its catalytic subunit. Hence, observations that levels of NOX4 in vascular cells are downregulated, ${ }^{36,37}$ unchanged, ${ }^{38}$ or upregulated, ${ }^{39,40}$ depending on the pathologic stimulus under investigation, provide no clear indication of a homeostatic versus pathophysiologic function of the catalytic subunit. Consistent with this, several reports suggest a role for NOX4 in promoting endothelial cell survival, proliferation, and migration, ${ }^{41-44}$ whereas other studies indicate that NOX4 mediates effects such as endoplasmic reticulum stress, oxidative DNA damage, and apoptotic and necrotic cell death of endothelial cells. ${ }^{40,45-47}$ Likewise, in vascular smooth muscle cells, NOX4 was initially described as a key regulator of cellular differentiation and quiescence, ${ }^{48,49}$ which is suggestive of a homeostatic function, but was subsequently shown to contribute to vascular smooth muscle cell proliferation, migration, and hypertrophy under certain conditions, ${ }^{50,51}$ all of which are important in arterial remodeling and atherogenesis.

Finally, even the fact that NOX4 generates hydrogen peroxide, which is capable of activating proinflammatory signaling cascades, ${ }^{52}$ rather than superoxide, ${ }^{53-55}$ raises questions as to whether NOX4 is likely to have a protective or detrimental role in vascular disease.

Indeed, in human microvascular endothelial cell lines and primary aortic vascular smooth cells, NOX5 activity was augmented by relevant proatherogenic stimuli, including thrombin, platelet-derived growth factor, angiotensin II, and endothelin 1; in each instance, NOX5 activity was suppressed following depletion of intracellular calcium. ${ }^{56,57}$ Endothelial cells and coronary arteries from patients with coronary artery disease showed greater NOX5 subunit expression and calcium-dependent ROS production compared with those from healthy subjects. ${ }^{58}$ Importantly, calcium-dependent but not calcium-independent ROS production was reduced by small interfering RNA against NOX5, indicating that calcium-dependent production of ROS is due to NOX5 activity. ${ }^{58}$ Although these data suggest a strong association between NOX5 activity and coronary artery disease in humans, evidence for a cause-effect relationship is not yet proven, and additional work is needed to characterize its physiologic and pathologic roles in the arterial wall.

Recent research has shown that NOX enzymes are particularly relevant in ischemia-reperfusion injury, a situation where a tissue is deprived of oxygen for a long period of time, followed by an abrupt increase in oxygen concentrations, eg, after thrombolysis in stroke and myocardial infarction or after surgical intervention. NOX are determinants of endothelial function after ischemiareperfusion injury. ${ }^{59}$

On the other hand, the situation is slightly different in the vascular system of the brain. All of the major cell types present in brain tissue, including neurons, astrocytes, microglia, and vascular endothelial cells, constitutively express NOX1, NOX2, and NOX $4,{ }^{60}$ which presumably reflects the physiologic roles of NOX-derived ROS in brain function. However, cerebral arteries differ from many noncerebral arteries in that they have higher levels of NADPH oxidase activity, ${ }^{61,62}$ and ROS more typically elicit marked vasorelaxant responses in cerebral vessels. ${ }^{17}$ If NADPH oxidase-derived ROS help to maintain cerebral blood flow and neural function, then great caution will be needed in developing future therapeutic strategies involving inhibition of brain NADPH oxidases.

There is evidence from studies of global NOX2 knockout mice that elevated activity of NADPH oxidase isoforms normally contributes to worsened outcomes following stroke, at least in males, ${ }^{63-67}$ and that the protective effects of apocynin occur via inhibition of NOX2. ${ }^{63,67,68}$ There is evidence that NOX4-derived ROS mediate cerebral endothelial apoptosis induced by tumor necrosis factor $(\mathrm{TNF})^{40}$ and infarct damage after stroke. ${ }^{69}$ However, there is conflicting evidence as to whether NOX1 activity might contribute to stroke damage..$^{70,71}$

\section{Heart failure}

Even more than nitric oxide depletion, endothelial nitric oxide synthase uncoupling, and modulation of intracellular redox signaling pathways, ROS also affect cellular energetics in the myocardium, resulting in an energy deficit, cellular damage, and acceleration of cell death via apoptosis and necrosis. ${ }^{72}$ Further, ROS modulate proliferation of fibroblasts, synthesis of collagen, and activation of matrix metalloproteinases, and their expression in the myocardium causes myocardial hypertrophy, fibrosis, and necrosis, which can lead to endothelial and myocardial dysfunction. ${ }^{73,74}$ At the subcellular level, ROS have been shown to be involved in the pathophysiology of pressure overload-induced left ventricular hypertrophy and heart failure. ${ }^{75}$ ROS are implicated not only in the process of cellular hypertrophy and remodeling in the decompensated phase, but also in the development of compensated pressure overload left ventricular hypertrophy. ${ }^{76}$

In $N O X 2^{y /-}$ (NOX2-deficient) mice in which pressure overload was induced by constriction of the ascending aorta, there was a large increase in messenger $(\mathrm{m}) \mathrm{RNA}$ expression of $\mathrm{p} 22$ phox and a small increase in mRNA expression of 
p47phox, whereas in wild-type mice there was a moderate increase in p22phox and no increase in p 47phox. ROS levels in the myocardium were two times higher than in wild-type mice. ${ }^{77}$ Bendall et $\mathrm{al}^{78}$ and Byrne et $\mathrm{a}^{79}$ reported contrasting roles for NOX isoforms in pressure overload-induced versus angiotensin II-induced myocardial hypertrophy using $\mathrm{NOX}^{--/}$mice in which hypertrophy was induced by transaortic constriction or chronic angiotensin II infusion, respectively. All these findings indicate that the function of cardiac NADPH oxidases depends on the isoform and also on the specific pathologic process involved.

The NOX2 isoform and the subunits of the enzyme complex associated to it were identified as a major source of ROS in left ventricular hypertrophy induced by pressure overload, and contributed to pathophysiologic changes, such as activation of redox-sensitive kinases and progression of heart failure. ${ }^{80}$

Studies of $\mathrm{NOX}_{4--}$ and cardiac-specific $\mathrm{NOX}_{4}^{--}\left(\mathrm{CNOX}_{4}^{--}\right)$ mice demonstrated the important role of NOX4, although contrasting results have been observed. It was seen that attenuated left ventricular hypertrophy, interstitial fibrosis and apoptosis, and systolic function were improved in

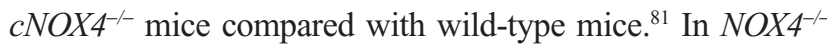
mice and a cardiomyocyte-targeted NOX4 transgenic model, with the latter overexpressing NOX4 in the heart, NOX4 expression was increased in cardiomyocytes in response to pressure overload and after myocardial infarction. However, $\mathrm{NOX}^{-/-}$mice showed significantly more cardiac dilatation and contractile deterioration compared with wild-type mice, and NOX4 transgenic mice developed less hypertrophy and fibrosis compared with wild-type mice. ${ }^{82}$ These data suggest that endogenous NOX4 has an important role in mediating cardiomyocyte hypertrophy, fibrosis, and apoptosis in response to pressure overload, although the mechanism of action remains undefined.

NOX2 is a relevant source of ROS in the pathogenesis of ischemic cardiomyopathy. It is unquestionable that NOX2 contributes to cardiac remodeling processes after myocardial infarction, because deletion of NOX2 significantly abrogates the effects. ${ }^{83}$ Nevertheless, the infarct size, measured before and after remodeling, was comparable between $N O X 2^{y /-}$ and wild-type mice, ${ }^{83} p 47 p h o x^{-/}$and heterozygous control mice, ${ }^{84}$ and $p 47 p h o x^{-/}$and wild-type mice. ${ }^{85}$ It appears that the role of NOX2-derived ROS depends crucially on the basal level of ROS production; loss of NOX2-derived ROS under physiologic conditions where it plays a proangiogenic role is detrimental, whereas loss of NOX2 in pathophysiologic conditions, when overall production is increased, is beneficial.

\section{Hypertension}

There is abundant evidence that ROS contribute to the pathophysiology of hypertension, and many mechanisms have been implicated. As we have previously commented, increased production of superoxide anions leads to a reduction in bioavailability of the vasodilator, nitric oxide. Further, ROS have been implicated in proliferation and hypertrophy of vascular resistance. ${ }^{11,12,86}$ There is genetic evidence from mice, rats, and humans to suggest a role of NOX in hypertension. In vascular smooth muscle cells, NOX1 is localized to the plasma membrane, caveolae, and endosomes, and its expression is induced by several substances, including vasoactive agonists, growth factors, proinflammatory cytokines, and advanced glycation end products. ${ }^{87}$ Studies in animal models of cardiovascular disease, especially of angiotensin II-induced hypertension, implicate this NADPH oxidase isoform as an important contributor to the pathology of cardiovascular disease.

NOX1 expression in the vascular wall is elevated in several in vivo animal models of hypertension. ${ }^{88-92}$ Accordingly, vascular superoxide production, endothelial dysfunction, and aortic hypertrophy were exacerbated in transgenic mice overexpressing NOX1 in vascular smooth muscle cells. ${ }^{93,94}$ These parameters were blunted in mice that were globally deficient in NOX1. ${ }^{95,96}$ However, NOX1 is associated with angiotensin II-dependent hypertension more than with noradrenaline-dependent hypertension. ${ }^{97}$

Spontaneously hypertensive rats have a polymorphism in the promoter of the p22phox gene, a subunit of the NADPH oxidase complex, that leads to an overexpression of this subunit and a subsequent increase in ROS. Humans homozygous for a polymorphism in the gene encoding p22phox have reduced oxidative stress in the vascular system and probably also reduced blood pressure..$^{98,99}$

It is likely that the type of experimental hypertension and the location of the blood vessel studied can significantly impact how NOX4 expression is regulated. In the absence of pathogenic stimuli, NOX4 knockout mice do not have an obvious phenotype and are normotensive. ${ }^{28}$

NOX4 is strongly expressed in the media of small pulmonary arteries and is causally involved in development of pulmonary hypertension. ${ }^{100}$ NOX4 is the major NADPH oxidase homologue expressed in human pulmonary artery smooth muscle cells, ${ }^{51}$ and its expression at both the mRNA and protein levels is significantly increased in lungs from patients with idiopathic pulmonary arterial hypertension compared with healthy lungs, ${ }^{100}$ suggesting a correlation between NOX4 and onset of pulmonary arterial hypertension. 


\section{Current status of pharmacologic research on NADPH oxidase}

In the previous section, we highlighted the value of targeting NADPH oxidase activity for cardiovascular problems. From this starting point, intense research has been undertaken in this field to answer two important questions, ie, where to act and how to do it, meaning that we still do not know what is the best molecular target or the best inhibitor.

\section{Points of targeting}

NADPH oxidases are involved in complex mechanisms of action. Therefore, targeting these enzymes can be done at several different points of the pathways involved. It is also important to define the aim of the strategy of inhibition in terms of whether all known oxidases should be simultaneously inhibited or only specific NADPH oxidase isoforms. Equally, the subcellular location of NADPH oxidases could be critical for the expected effect of the inhibition, because local ROS production in different subcellular compartments has different pathophysiologic significance.

Moreover, some different mechanisms could be used to inhibit NADPH oxidase activity. Decreasing expression of the catalytic subunits or their regulatory subunits is one possibility. Activation of the enzyme complex can be also decreased by blocking translocation of the cytosolic subunits to the membrane or inhibiting activation of the regulatory subunits. A decrease in the signal transduction pathways upstream of NADPH oxidase activation is an indirect way to inhibit the activity of the enzyme. Finally, we consider direct inhibition of some or specific NADPH oxidase subunits. All together, they form the available "points of targeting" which should guide the final objective: NADPH oxidase inhibition. We will make some considerations about these points before reviewing the currently available inhibitory drugs or strategies.

\section{NADPH isoforms}

As we have seen, the evidence for the seven NOX isoforms is not equal. The main volume of research in all fields and particularly in the cardiovascular field includes NOX1, NOX2, and NOX4. Little is known about the involvement of NOX5 in cardiovascular disease and almost nothing is known about NOX3, DUOX1, and DUOX2. This may or may not reflect the real involvement of each isoform in the pathophysiologic process, and be an indication for future research. Therefore, the state of the art at the moment points to NOX2 in several cell types, and to a lesser extent NOX1 in vascular smooth muscle cells, as the NADPH oxidases that currently represent the most promising therapeutic targets for treating vascular diseases. However, NOX4 and NOX5 could emerge as validated drug targets from future research.

There is a strong rationale for therapeutically targeting NOX2 in the arterial wall for the treatment of vascular disease because this isoform can generate large amounts of ROS, and pharmacologic inhibition or genetic deletion reduces vascular oxidative stress in several disease models. ${ }^{63,67,68,101-105}$

Studies in animal models implicate NOX1 as an important contributor to the pathology of cardiovascular disease. Expression of NOX1 in the vascular wall is elevated in several in vivo animal models of hypertension. ${ }^{88-92} \mathrm{In}$ mice overexpressing NOX1 in vascular smooth muscle cells, angiotensin II-induced hypertension, endothelial dysfunction, and aortic hypertrophy were exacerbated..$^{93,94}$ Finally, expression of NOX1 is elevated in atherosclerotic lesions from apolipoprotein E-deficient $\left(\mathrm{ApoE}^{-/}\right)$mice and humans. ${ }^{31,32}$ In addition, greater reduction in development of atherosclerotic lesions in the aorta of the $\mathrm{NoxI}^{-1-} / \mathrm{ApoE}^{-/-}$ double knockout mice has been observed. ${ }^{33}$

There is no clear indication of a homeostatic versus pathophysiologic function of NOX4 in vascular cells. In fact, NOX4 has been associated with beneficial effects ${ }^{41-44}$ and detrimental effects. ${ }^{40,45-47}$ Therefore, this NADPH oxidase isoform could participate in positive arterial remodeling or in atherosclerosis, depending on the physiologic conditions. NOX5 seems to function as a stand-alone protein and has a calcium-binding domain, which allows NOX5 activity to be regulated by increases in the cytosolic concentration of calcium. ${ }^{106}$ NOX5 activity in vascular cells responds to proatherogenic stimuli and is suppressed by depletion of intracellular calcium..$^{37,57}$ NOX5 expression is greater in endothelial cells and coronary arteries from patients with coronary artery disease compared with those from healthy subjects. ${ }^{58}$ Although these data suggest a strong association between NOX5 activity and coronary artery disease, evidence for a cause-effect relationship is not yet proven, and further research is needed to characterize this association.

\section{Subcellular location of NADPH oxidases}

Because ROS are diffusible and short-lived, subcellular localization of NOX isoforms is crucial in their activation, in the site of ROS production, and in the coordination of redox-signaling events. NOX isoforms are now recognized to have specific subcellular localizations defined by their unique localization motifs that bind to adaptor proteins and target their cargo to the correct membrane. NADPH oxidases appear to be activated within discrete subcellular compartments, including caveolae/lipid rafts, focal adhesions, 
cell-cell contacts, lamellipodial leading edges, endosomes, and the nucleus. ${ }^{107}$ This facilitates spatially confined ROS production with redox-sensitive targets in proximity, which may allow ROS to activate specific redox-signaling events. However, the mechanisms by which NOX isoforms traffic to the correct subcellular location in order to accomplish appropriate signaling remains poorly defined.

In vascular smooth muscle cells, stimulation of angiotensin II promotes angiotensin type 1 receptor (AT1) trafficking into caveolin-1-enriched membrane fractions where NOX1 is found. ${ }^{108}$ This causes localized production of ROS and ROScSrc-dependent transactivation of the epidermal growth factor receptor (EGFR) and its egress from caveolae. Tyrosinephosphorylated EGFR and caveolin-1 subsequently appear at focal adhesions where NOX4 and paxillin localize, thereby forming redox signaling platforms. ${ }^{109,110}$ These events are essential for activation of specific redox signaling pathways involved in vascular smooth muscle cell hypertrophy. ${ }^{111}$ For instance, treatment with TNF- $\alpha$ causes activation of NOX1 and generation of ROS within endosomes with subsequent nuclear factor kappa-light-chain-enhancer of activated B cells (NF-KB) activation. ${ }^{112,113}$ However, treatment with thrombin causes nonendosomal NOX1-dependent production of ROS, which, as in the case of stimulation with angiotensin II, leads to transactivation of EGFR. ${ }^{112}$

In endothelial cells, stimulation with TNF- $\alpha$, Fas ligand, and shear stress induces recruitment of NOX2, p47phox, and Rac1 into lipid rafts, ${ }^{114}$ thereby promoting raft-localized activation of NADPH oxidase and production of ROS and endothelium-derived nitric oxide synthase (NOS) within raft domains. This formation of redox signaling platforms in caveolae/lipid rafts in which death receptors couple to NADPH oxidase contributes to a decrease in bioavailability of nitric oxide and production of peroxynitrite, ${ }^{115}$ which uncouples NOS to produce more superoxide anions and finally contributes to endothelial dysfunction. ${ }^{116}$

Integrin-mediated cell adhesion (focal adhesions and cell-matrix adhesion sites) serve as organizing centers for regulatory and structural proteins to facilitate rapid and precise control of cell functions like gene transcription for cell proliferation, survival, motility, and cytoskeletal remodeling. ${ }^{17-121}$ A synergistic action of integrins and receptor tyrosine kinases occurs during redox signaling. ${ }^{122}$ Growth factor activates NADPH oxidase, whereas activation of integrin stimulates the mitochondria and 5-lipooxygenase to generate localized production of ROS at cell-matrix adhesions. These ROS induce oxidative inactivation of protein tyrosine phosphatases, ${ }^{123-126}$ which negatively regulate receptor tyrosine kinase and focal adhesion kinase, thereby promoting downstream redox signaling events leading to proliferation, survival, and gene expression. ${ }^{122}$

The molecule primarily responsible for cell-cell contacts of endothelial cells is vascular endothelialcadherin. ${ }^{127}$ Tyrosine phosphorylation of the vascular endothelial-cadherin complex is required for disruption of the cell-cell junction, ${ }^{128-130}$ and is mediated via cSrc, which is dependent on ROS. ${ }^{131,132}$ Moreover, NADPH oxidase-derived ROS are involved in vascular endothelialcadherin/ $\beta$-catenin phosphorylation and disruption of cellcell contacts. ${ }^{133}$ Stimulation of vascular endothelial growth factor promotes loss of cell-cell contacts, thereby promoting migration and proliferation of endothelial cells involved in angiogenesis as well as endothelial permeability via a ROSdependent mechanism. ${ }^{134,135}$ Polymorphonuclear leukocyte adhesion to endothelial cells stimulates production of ROS, which also promote loss of cell-cell adhesions through phosphorylation of vascular endothelial-cadherin. ${ }^{136}$ These responses are involved in increasing transendothelial migration of polymorphonuclear leukocytes and endothelial permeability, which contributes to inflammatory diseases, such as atherosclerosis and diabetes. Thus, NADPH oxidase-derived ROS produced near the adherent junction may activate redox signaling that disrupts cell-cell contacts, promoting angiogenesis, vascular inflammation, and permeability. ${ }^{131,137}$

Migration of endothelial cells is a key event for tissue repair in response to injury, angiogenesis, and wound healing. In these cells, Rac1-dependent and NOX2-dependent NADPH oxidase plays an important role in cell migration. ${ }^{12,138-140}$ NOX2 and its regulatory subunits are targeted to the focal complexes or membrane ruffles in lamellipodia. ${ }^{141-143}$ Oxidants derived from activation of NADPH oxidase and lamellipodial dynamics are likely to be spatially and functionally coupled at the leading edge to promote directional cell migration. ${ }^{143,144}$ Different functional and scaffold proteins, such as WAVE1, ${ }^{141,145}$ IQGAP $1,{ }^{146,147}$ and protein tyrosine phosphatase-PEST, ${ }^{142}$ have been associated with NADPH oxidase complexes in leading edges of lamellipodia and focal contacts.

The NADPH oxidase complex is also formed in intracellular compartments. NOX2, ${ }^{148} \mathrm{NOX} 4,{ }^{149}$ or NOX1, NOX2, and NOX $4^{44}$ have been found in the perinuclear compartments of different types of endothelial cells. NOX4 is critical for oxidative inactivation of protein tyrosine phosphatase 1B localized mainly to the cytosolic face of the endoplasmic reticulum, thereby enhancing activation of receptor tyrosine kinase in this intracellular compartment. ${ }^{150}$ 
Stimulation of interleukin- $1 \beta$ promotes endocytosis of its receptor, which is required for NOX2-dependent ROS production in early endosomes and subsequent redoxdependent activation of the transcription factor, NF- $\mathrm{KB} .{ }^{151}$ NOX1 and NOX2 are also involved in endosomal production of ROS after hypoxia-reoxygenation injury required for inhibitory subunit of NF-kappa B alpha $(\mathrm{I} \kappa \mathrm{B} \alpha)$ tyrosine phosphorylation. ${ }^{152}$ NOX1 can also participate in the ROS production required for NF- $\kappa \mathrm{B}$ activation induced by TNF$\alpha .{ }^{113}$ Taken together, these studies suggest that NADPH oxidase-dependent ROS production in endosomes is involved in the proinflammatory immune response.

Many transcription factors are redox-sensitive, including activator protein 1 (AP-1), NF- $\mathrm{B}, \mathrm{Nrf2}, \mathrm{p} 53$, and the glucocorticoid receptor, ${ }^{153-158}$ which require an oxidative signal in the cytoplasm to initiate signaling for activation, whereas oxidative stress in the nuclear compartment blocks the process. ${ }^{159}$ NOX4 preferentially localizes to the nucleus in human endothelial cells, ${ }^{160}$ so local NOX4-dependent ROS production in the nucleus may contribute to regulation of the redoxdependent transcription factor and gene expression involved in cell growth, differentiation, senescence, and apoptosis.

A better understanding of compartmentalization of redox signaling will provide further insights into temporally and spatially organized ROS-dependent signaling systems and the relevance of antioxidant therapy, with targeting to specific intracellular microdomains for the treatment of various oxidant stress-dependent diseases.

\section{Expression of NADPH oxidase}

NOX isoforms are differentially expressed during development of atherosclerosis. Expression of NOX4 appears to increase the stability of atherosclerotic plaques, while at earlier stages of plaque development NOX2 seems to predominate, contributing to progression of atherosclerosis. ${ }^{161}$ This led to the conclusion that NOX4 might be involved in the maintenance of the differentiated vascular smooth muscle cell phenotype. ${ }^{48}$ NOX5 in turn seems to be coexpressed at sites of human plaque instability. ${ }^{58}$ These aspects point to the complex nature of regulation of NADPH oxidases and their role in disease. It is also clear that we must be cautious about the pharmacologic targeting of these enzymes in humans.

The natural or pathophysiologic expression of NADPH oxidases in the vasculature can also be modified by selected drugs, which clearly introduces a new point of targeting. Docosahexaenoic acid has been demonstrated to decrease NOX4 expression and activity in human aortic endothelial cells, an effect associated with reduced production of ROS. ${ }^{162}$ In the same way, resveratrol, a natural occurring antioxidant found in grapes and wine, downregulates NOX4 in a concentration-dependent way in human endothelial cells, on the contrary, it upregulates the expression of two antioxidative enzymes, ie, superoxide dismutase and glutathione peroxidase $1 .{ }^{163}$

Pathophysiologic upregulation of NADPH oxidase expression could be also selectively inhibited by some drugs. Sodium hydrosulfide and the $\mathrm{H}_{2} \mathrm{~S}$-donating derivative of sildenafil (ACS6) completely inhibited NOX2 expression induced by TNF- $\alpha$ in porcine endothelial cells via the adenylyl cyclase-protein kinase A pathway. ${ }^{164}$ Expression of p47phox could also be inhibited, but it is not clear if this effect is due to hydrosulfide or to the sildenafil structure. ${ }^{165}$ CPU0213, an endothelin receptor antagonist, reversed the upregulation of p22phox and p47phox (NADPH oxidase regulatory subunits) induced by administration of isoproterenol, a beta-adrenergic sympathomimetic, in rats. ${ }^{166}$ In rats with hypertension induced by deoxycorticosterone acetate (DOCA) salt, dietary sesamin prevented the enhanced increase in NADPH oxidase activity and expression. ${ }^{91}$ Many other natural products have been shown to reduce expression of NADPH oxidase in vascular tissues. ${ }^{163,167-173}$ One of the main transcription factors implicated in TNF- $\alpha$-induced or angiotensin II-induced upregulation of NOX isoforms and NADPH oxidase subunits is AP-1. ${ }^{174}$ In contrast, enhanced expression of NOX1, NOX2, NOX4, and p22phox by nonselective, nonsteroidal anti-inflammatory drugs has been demonstrated in the aorta and heart in animal models, in isolated human endothelial cells, and in healthy volunteers. ${ }^{175}$

This picture is further complicated by the fact that genetic variation of NADPH oxidase components, which is related to differential ROS production, is involved in atherosclerosis and vascular dysfunction. Genetic variation of the p22phox subunit encoding gene $C Y B A$ has been discussed in this context; however, all other subunits should be carefully examined also in the context of pharmacokinetics and immunogenetics. ${ }^{23,58,161,176}$ Although expression of p22phox is not affected, the C242T CYBA single nucleotide polymorphism is associated with altered NADPH oxidase activity in patients with cardiovascular disease. ${ }^{98}$

\section{Direct inhibition or modulation of regulatory pathways}

Due to the complex relationship between NADPH oxidases and other proteins in the context of some signaling pathways and even the complex cross-talk between different signaling 
pathways, inhibition of NADPH oxidase activity can be done sometimes via regulation of a pathway rather than direct inhibition of the oxidase. This possibility has been considered in clinical practice because it has not been easy to obtain specific and selective inhibitors for each NADPH oxidase isoform. Therefore, at the moment, direct and indirect inhibition of NADPH oxidase activity should be considered as strategies with the same objective (Figure 4).

\section{Suitable inhibitors}

Multiple lines of evidence for inhibition of NADPH oxidase are required to confirm the inhibitory effect. Therefore, several approaches can be used to investigate the inhibitory effect and to discriminate between compounds that act directly on the enzyme complex versus the activation process upstream of NADPH oxidase. For a summary of these approaches, see the review by Jaquet et al. ${ }^{177}$ We discuss below the available NADPH oxidase inhibitors differentiated by these general mechanisms of action. Other authors have grouped the NADPH oxidase inhibitors by more precise steps of NADPH oxidase activation. In this regard, it is useful to consult the review of Streeter et al, ${ }^{178}$ which included the following steps as possible targets: NOX expression, signal transduction upstream of NOX activation, trafficking of NOX to the appropriate subcellular compartment, assembly of NADPH oxidase complex, electron transfer from NADPH to oxygen, and oxidation of downstream targets.

\section{Direct inhibitors: past and future}

Several compounds have the ability to inhibit NADPH oxidases directly (Table 1). In many cases, their effects have been confirmed in vivo, but major problems with the inhibitors currently available include low specificity, associated toxicity, or their peptide character. The search for successful inhibitors continues as the prospect for use in clinical practice increases along with molecular knowledge about redox signaling (Figure 5). Specific inhibitors are also essential to establish fully the role of NADPH oxidases and individual NOX isoforms in different pathologies.

\section{Small-molecule NADPH oxidase inhibitors}

Old and new NADPH oxidase inhibitors are presented in Table 1. The first inhibitors used were diphenyleneiodonium and apocynin, a naturally occurring inhibitor originally isolated from the roots of Picrorhiza kurroa. These have been the most widely studied and used as pharmacologic tools. However, they lack selectivity for NADPH oxidases. Diphenyleneiodonium inhibits flavin oxidases, thus affecting numerous enzymes. ${ }^{179,180}$ Apocynin is an orally active agent that acts as a prodrug, requiring a reaction with peroxidase to be able to block assembly of NADPH oxidase. ${ }^{181}$ Its possible therapeutic value has been probed in animal models, where it blunted the development of hypertension and prevented endothelial dysfunction in rats rendered hypertensive by DOCA salt. ${ }^{182}$ However, apocynin

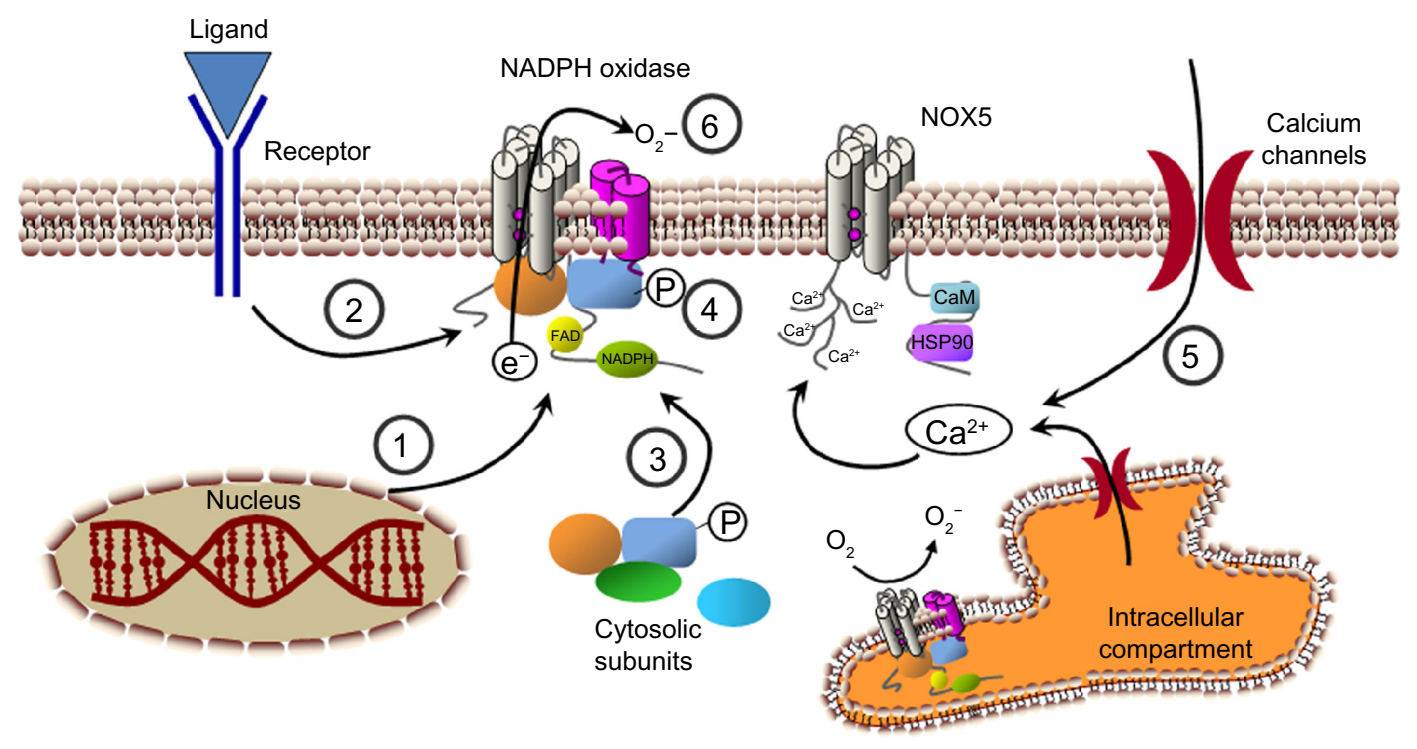

Figure 4 Possible strategies for NADPH oxidase inhibition. Several steps that can be used to modulate NADPH oxidase activity. (I) NADPH oxidase subunits expression. (2) Signaling upstream of NADPH oxidase activation. (3) Association of cytosolic subunits and formation of the complete enzyme complex. (4) Subunit phosphorylation (P) and activation. (5) Modulation of cytosolic calcium concentration. (6) Transference of electrons through the enzyme complex.

Abbreviations: $\mathrm{Ca}^{2+}$, calcium ion; $\mathrm{CaM}$, calmodulin; $\mathrm{e}^{-}$, electron; $\mathrm{FAD}$, flavin adenine dinucleotide; HSP90, heat shock protein 90 ; NADPH, nicotinamide adenine dinucleotide phosphate; $\mathrm{O}_{2}$, superoxide anion; $\mathrm{O}_{2}$, oxygen. 
Table I Direct inhibitors of NADPH oxidase activity

\begin{tabular}{|c|c|c|c|}
\hline Compound & Mechanism of action & Other pharmacologic effects & Reference \\
\hline \multicolumn{4}{|l|}{ Small molecules } \\
\hline Diphenyleneiodonium & $\begin{array}{l}\text { Flavoprotein inhibitor and prevents electron flow } \\
\text { through the enzyme }\end{array}$ & $\begin{array}{l}\text { Inhibitor of all flavin-containing proteins } \\
\text { (eg, NADPH dehydrogenase, xanthine } \\
\text { oxidase, nitric oxide synthase) }\end{array}$ & 179,180 \\
\hline Apocynin & $\begin{array}{l}\text { Oxidase assembly inhibitor, inhibits association } \\
\text { of p67phox subunit with membrane complex }\end{array}$ & $\begin{array}{l}\text { Scavenger of hydrogen peroxide; } \\
\text { interference with arachidonic acid } \\
\text { metabolism, glutathione synthesis, and AP-I } \\
\text { transcription factor activation }\end{array}$ & 181 \\
\hline Phenylarsine oxide & $\begin{array}{l}\text { Oxidase assembly inhibitor, prevents assembly } \\
\text { of an active oxidase complex by bond to vicinal } \\
\text { cysteine residues }\end{array}$ & $\begin{array}{l}\text { Its binding to vicinal cysteine residues makes } \\
\text { this agent an inhibitor of a variety of other } \\
\text { enzymes }\end{array}$ & 186,187 \\
\hline Gliotoxin & $\begin{array}{l}\text { Inhibits NOX } 2 \text { by preventing } \mathrm{p} 47 \text { phox } \\
\text { phosphorylation and assembly of the enzyme } \\
\text { complex reacting with thiol residues }\end{array}$ & None reported & $54,190,19 \mid$ \\
\hline $\begin{array}{l}\text { Aminoethyl } \\
\text { benzenesulphonyl } \\
\text { fluoride }\end{array}$ & $\begin{array}{l}\text { Oxidase assembly inhibitor, inhibits association } \\
\text { of NOX2 subunit with p47phox }\end{array}$ & $\begin{array}{l}\text { Nonselective serine protease inhibitor, } \\
\text { interfering with commonly used assays } \\
\text { for ROS }\end{array}$ & 192 \\
\hline VAS2870 & $\begin{array}{l}\text { Undefined mechanism of action; inhibition of } \\
\text { NADPH oxidase activity in cells containing NOX2 } \\
\text { and NOX } 4\end{array}$ & $\begin{array}{l}\text { No inhibition of xanthine oxidase, no } \\
\text { superoxide anion scavenging }\end{array}$ & 193,194 \\
\hline VAS3947 & $\begin{array}{l}\text { Undefined mechanism of action; inhibition of NADPH } \\
\text { oxidase activity independently of the specific isoform } \\
\text { expressed }\end{array}$ & $\begin{array}{l}\text { No inhibition of xanthine oxidase and nitric } \\
\text { oxide synthase; no superoxide anion } \\
\text { scavenging; no interference with commonly } \\
\text { used assays for ROS }\end{array}$ & 193 \\
\hline GK-13690I & $\begin{array}{l}\text { It has been suggested that it may act as a competitor } \\
\text { of the substrate of the enzyme }\end{array}$ & $\begin{array}{l}\text { No inhibition of xanthine oxidase, no } \\
\text { superoxide anion scavenging }\end{array}$ & 196 \\
\hline SI7834 & $\begin{array}{l}\text { Prevention of cytosolic subunits, mainly p47phox, } \\
\text { binding to the membrane complex of the enzyme; } \\
\text { possible direct inhibition }\end{array}$ & $\begin{array}{l}\text { No inhibition of xanthine oxidase, no } \\
\text { superoxide anion scavenging }\end{array}$ & 198 \\
\hline Plumbagin & Undefined mechanism of action & & 201 \\
\hline MLI7I & Selectivity for NOXI & $\begin{array}{l}\text { No inhibition of xanthine oxidase, no } \\
\text { hydrogen peroxide scavenging }\end{array}$ & 203 \\
\hline Fulvene-5 & NOX2 and NOX4 inhibition & None reported & 204 \\
\hline Ebselen & $\begin{array}{l}\text { Oxidase assembly inhibitor, inhibits binding } \\
\text { of p22phox and p47phox subunits }\end{array}$ & Hydrogen peroxide scavenger & 231 \\
\hline $\begin{array}{l}\mathrm{N}-(\text { I-cyclohexylethyl)-4- } \\
\text { phenylphthalazin-I-amine }\end{array}$ & $\begin{array}{l}\text { Undefined mechanism of action, inhibition } \\
\text { of superoxide anion production in diabetic aorta }\end{array}$ & None reported & 177 \\
\hline $\begin{array}{l}\text { Pyrazolo }(1.5-\mathrm{A}) \\
\text { pyrimidines }\end{array}$ & $\begin{array}{l}\text { Undefined mechanism of action, inhibition } \\
\text { of NADPH oxidases in neutrophils and blood vessels }\end{array}$ & None reported & 177 \\
\hline Pyazolo pyridines & Unspecific inhibition of all NOX isoforms & None reported & 177 \\
\hline Tetrahydroindoles & Unspecific inhibition of all NOX isoforms & None reported & 177 \\
\hline \multicolumn{4}{|l|}{ Peptide inhibitors } \\
\hline Nox2ds-tat & $\begin{array}{l}\text { Oxidase assembly inhibitor: inhibits association } \\
\text { of NOX2 with p } 47 \text { phox subunit }\end{array}$ & No superoxide anion scavenging & 206 \\
\hline Nox2ds & $\begin{array}{l}\text { Mimics a sequence in the cytosolic B-loop of NOX2 } \\
\text { and specifically inhibits superoxide anion production } \\
\text { by this isoform }\end{array}$ & None reported & 207 \\
\hline PR39 protein & $\begin{array}{l}\text { Oxidase assembly inhibitor: binds to } \mathrm{SH} 3 \text { domain } \\
\text { of } \mathrm{p} 47 \text { phox subunits, limiting its regulatory activity }\end{array}$ & $\begin{array}{l}\text { Not selective for NADPH oxidase } \\
\text { because it can inhibit other protein } \\
\text { with } \mathrm{SH} 3 \text { domains }\end{array}$ & 208 \\
\hline \multicolumn{4}{|c|}{ Naturally occurring antioxidants } \\
\hline Procyanidins from grapes & $\begin{array}{l}\text { Inhibition of NADPH oxidase activity in endothelial } \\
\text { cells and cell-disrupted systems }\end{array}$ & $\begin{array}{l}\text { Superoxide anion scavenging at high } \\
\text { concentrations }\end{array}$ & 215 \\
\hline $\begin{array}{l}\text { Flavonoids from Inula } \\
\text { Britannica } L\end{array}$ & $\begin{array}{l}\text { Reduction of p } 47 \text { phox expression and phosphorylation } \\
\text { in vascular smooth muscle cells }\end{array}$ & None reported & 168 \\
\hline Ginkgolide B & $\begin{array}{l}\text { Attenuation of enhancement of NOX } 4 \text { expression } \\
\text { and ROS generation in human endothelial cells }\end{array}$ & None reported & 170 \\
\hline
\end{tabular}

\section{Small molecules}

phenyleneiodonium

avoprotein inhibitor and prevents electron flow

Oxidase assembly inhibitor, inhibits association

of p67phox subunit with membrane complex

Xxidase assembly inhibitor, prevents assembly cysteine residues

thiol residues

Undefined mechanism of action; inhibition of

Undefined mechanism of action; inhibition of NADPH oxidase activity independently of the specific isoform

\section{of the substrate of the enzym}

binding to the membrane complex of the enzyme;

Plumbagin

Undefined mechanism of action

NOX2 and NOX4 inhibition

of p22phox and p47phox subunits

of superoxide anion production in diabetic aorta

Unspecific inhibition of all NOX isoforms

Oxidase assembly inhibitor: inhibits association

Mimics a sequence in the cytosolic B-loop of NOX2

and specifically inhibits superoxide anion production

Oxidase assembly inhibitor: binds to $\mathrm{SH} 3$ domain

(eg, NADPH dehydrogenase, xanthine

oxidase, nitric oxide synthase)

Scavenger of hydrogen peroxide;

metabolism, glutathione synthesis, and AP-I

transcription factor activation enzymes

interfering with commonly used assays

for ROS

No inhibition of xanthine oxidase, no

No inhibition of xanthine oxidase and nitric used assays for ROS

No inhibition of xanthine oxidase, no

oxidase, no

No inhibition of xanthine oxidase, no

xide scavenging

None reported

None reported 
Table I (Continued)

\begin{tabular}{|c|c|c|c|}
\hline Compound & Mechanism of action & Other pharmacologic effects & Reference \\
\hline Rutaecarpine & $\begin{array}{l}\text { Reversal of upregulation of NOX2, NOX4, } \\
\text { and p47phox in myocardial cells }\end{array}$ & None reported & I7I \\
\hline Reinioside C & $\begin{array}{l}\text { Reversal of NADPH oxidase subunit upregulation } \\
\text { (NOX2 and p22phox) }\end{array}$ & None reported & 172 \\
\hline Resveratrol & $\begin{array}{l}\text { Inhibition of NADPH oxidase activity; downregulation } \\
\text { of NOX4 }\end{array}$ & $\begin{array}{l}\text { No superoxide anion scavenging; } \\
\text { upregulation of superoxide dismutase-I } \\
\text { and glutathione peroxidase I } \\
\text { (antioxidative enzymes) }\end{array}$ & 163,216 \\
\hline $\begin{array}{l}\text { Quercetin and } \\
\text { isorhamnetin }\end{array}$ & $\begin{array}{l}\text { Reduction of endothelin I-induced upregulation } \\
\text { of p } 47 \text { phox subunit }\end{array}$ & $\begin{array}{l}\text { Inhibition of protein kinase C; reduction } \\
\text { of endothelial NOS uncoupling }\end{array}$ & 173 \\
\hline Epicatechin & $\begin{array}{l}\text { Reduction of NADPH oxidase activity } \\
\text { and overexpression of p } 47 \text { phox and p22phox }\end{array}$ & None reported & 167,217 \\
\hline Tanshinone IIA & $\begin{array}{l}\text { Inhibition of increased NADPH oxidase activity } \\
\text { and expression in a model of hypertensive rats }\end{array}$ & None reported & 169 \\
\hline Folic acid & $\begin{array}{l}\text { Inhibition of NADPH oxidase activity by } \\
\text { an undefined mechanism }\end{array}$ & $\begin{array}{l}\text { Inhibition of xanthine oxidase activity } \\
\text { and restoration of superoxide dismutase } \\
\text { activity }\end{array}$ & 218 \\
\hline Magnolol & $\begin{array}{l}\text { Inhibition of NADPH oxidase after the enzyme } \\
\text { is activated }\end{array}$ & $\begin{array}{l}\text { No superoxide anion scavenging; blockade } \\
\text { of different protein kinases }\end{array}$ & 219 \\
\hline Honokiol & $\begin{array}{l}\text { Inhibition of NADPH oxidase after the enzyme } \\
\text { is activated }\end{array}$ & None reported & 221,222 \\
\hline Xuezhikang & $\begin{array}{l}\text { Decrease membrane translocation of } \mathrm{p} 47 \mathrm{phox} \text {, through } \\
\text { the inhibition of extracellular signal-regulated kinase } \\
\mathrm{I} / 2 \text { activation }\end{array}$ & None reported & 224 \\
\hline Puerarin & Inhibition of phosphorylation of p47phox and Racl & None reported & 225 \\
\hline Tripterine & $\begin{array}{l}\text { Prevention of Janus kinase-dependent induction } \\
\text { of NOXI }\end{array}$ & Prevents induction of nitric oxide synthase & 226 \\
\hline Celastrol & $\begin{array}{l}\text { Nonspecific inhibitor of NOXI, NOX2, NOX4, } \\
\text { and NOX5, with increased potency against NOXI } \\
\text { and NOX2; oxidase assembly inhibitor, inhibits } \\
\text { binding of p22phox and p47phox subunits }\end{array}$ & None reported & 227 \\
\hline
\end{tabular}

Abbreviations: AP-I, activator protein I; NADPH, nicotinamide adenine dinucleotide phosphate; NOX, NADPH oxidase; NOS, nitric oxide synthase; ROS, reactive oxygen species; $\mathrm{SH}$, Src-homology region 3.

seems to have effects other than inhibition of NADPH oxidase, interfering also with metabolism of arachidonic acid, ${ }^{183}$ synthesis of glutathione, and activation of AP-1 transcription factor. ${ }^{184}$ Further, it has recently been shown to be a direct ROS scavenger in certain experimental conditions. ${ }^{185}$

Phenylarsine oxide is a potent NOX2 inhibitor. It is ineffective once the oxidase complex is formed, suggesting that it prevents assembly of an active oxidase complex. Because phenylarsine oxide is known to form disulfide bonds with vicinal cysteine residues, it is postulated that these residues are only unmasked and accessible for phenylarsine oxide in the resting state of the NADPH oxidase complex. ${ }^{186}$ However, this chemical reactivity with cysteine residues is likely to make this agent an inhibitor of a variety of other enzymes. Phenylarsine oxide has been demonstrated to decrease NADPH oxidase-derived ROS production in rat arteries, ${ }^{187}$ and in vivo inhibited production of superoxide anions induced by angiotensin II and enhanced chronic heart failure in rabbits. ${ }^{188}$ However, it is also shown that phenylarsine oxide may induce ROS production dependent on NADPH oxidase, which may mediate other effects like protein expression. ${ }^{189}$

Gliotoxin is a mycotoxin extracted from Aspergillus species. It blocks NOX2 but is inefficient for NOX4 inhibition. ${ }^{54}$ Gliotoxin interferes with phosphorylation of $\mathrm{p} 47 \mathrm{phox},{ }^{190}$ but also directly affects NOX2 activity. ${ }^{191}$ It is speculated that gliotoxin acts by a mechanism similar to that of phenylarsine oxide.

Another chemical inhibitor of NADPH oxidase is aminoethyl benzenesulfonyl fluoride (AEBSF), but its action is at high concentrations (half maximal inhibitory concentration $\left[\mathrm{IC}_{50}\right]>1 \mathrm{mM}$ ) and it has off-target effects as a serine protease inhibitor. AEBSF interferes with the binding of p47phox and/or p67phox to the membrane of the NADPH oxidase complex, probably by a direct effect on NADPH oxidase. ${ }^{192}$ It also interferes with the most commonly used assays for ROS. ${ }^{193}$ 
VAS2870 is a cell-permeable thiotriazolopyrimidine compound that acts as a rapid and reversible inhibitor of NADPH oxidase activity. It does not seem to have direct ROS scavenging properties and had no effects on xanthine oxidasemediated superoxide production or on endothelial nitric oxide synthase activity. ${ }^{193,194}$ VAS2870 inhibited elevated ROS production and restored endothelium-dependent relaxation in aortas from spontaneously hypertensive rats ${ }^{38}$ and limited phenylephrine-induced contraction in rat tail arteries. ${ }^{195}$ Intrathecal administration of VAS2870 to mice following experimental stroke was shown to reduce brain infarct volume and improve the neurologic outcome. ${ }^{69}$ Interestingly, in this study, Nox $4^{-/-}$mice were similarly protected against brain infarction and neurologic deficits following stroke as those administered VAS2870. A more recently introduced triazolopyrimidine, VAS3947, has been shown to be relatively specific for NADPH oxidases versus nitric oxide synthase and xanthine oxidase, but it cannot be excluded that VAS3947 interferes with an alternative source of ROS, such as the mitochondrial electron chain. ${ }^{193}$

GK-136901 is a pyrazolopyridine derivative, structurally related to VAS2870 and VAS3947, and recently identified as a potent selective inhibitor of NOX1 and NOX4 isoformdependent ROS generation from disrupted cell membrane preparations; it had no detectable inhibitory effects against ROS generated in vitro by xanthine oxidase. GK-136901 has high oral bioavailability, lacks off-target effects against a panel of 135 enzymes, and has a good safety profile in vivo. ${ }^{196}$ All together, this makes it a good drug candidate as a NADPH oxidase inhibitor, and it has been shown to attenuate hypoxia-induced pulmonary vascular cell proliferation in mice, suggesting its value in pulmonary hypertension. ${ }^{197}$

S17834 blocks NADPH oxidase activity in intact endothelial cells and in isolated endothelial cell membranes without inhibiting ROS generated by xanthine oxidase in a cell-free preparation system, indicating that it does not have superoxide scavenger properties. ${ }^{198}$ Further, when administered to apolipoprotein E-deficient and low-density lipoprotein receptor-deficient mice, S17834 suppressed TNF-induced leukocyte adhesion, reduced expression of plasminogen activator inhibitor 1 , augmented nitric oxide production in endothelial monolayers, and showed atheroprotective properties. ${ }^{198-200}$ Its major mechanism of action involves prevention of binding of cytosolic subunits (mainly p47phox) to the membrane complex of the enzyme. Although its exact mechanism of action remains unclear, plumbagin, a plant-derived naphthoquinone, has been used to inhibit NADPH oxidase-dependent superoxide production in cell lines that express $\mathrm{NOX}^{201}$ and as an antiatherosclerotic drug in animals. ${ }^{202}$

Several phenothiazines have been identified as NOX1 inhibitors by high-throughput screening using an HT29 cell-based assay. ${ }^{203}$ The inhibitor 2-acetylphenothiazine (ML171) had an $\mathrm{IC}_{50}$ for NOX1 in the nanomolar range, whereas the $\mathrm{IC}_{50}$ values for NOX2, NOX3, and NOX4 were in the micromolar range, similar to the $\mathrm{IC}_{50}$ value for xanthine oxidase. NOX5 was not included in the assays. ML171 appears to target the NOX1 catalytic subunit but not its cytosolic regulators. Due to the presence of the phenothiazine structure, a possible side effect of ML171 is a potential antipsychotic action. However, binding assays for a large battery of human receptors and channels in the central nervous system led to the conclusion that ML171 does not likely exert unwanted antipsychotic effects. ${ }^{203}$

Fulvene-5 is a recently described NADPH oxidase inhibitor from the family of fulvenes, which are highly watersoluble aromatic ring structures. Fulvene- 5 showed inhibitory activity against NOX2 and NOX4. However, there are no data on the $\mathrm{IC}_{50}$ values or its specificity and activity toward other NOX isoforms. ${ }^{204}$ Although little public information is available, some other small NADPH oxidase inhibitors have been investigated by pharmaceutical companies. An overview of some of these products can be found in the review published by Jaquet et al. ${ }^{177}$

In some cases, comparative studies between old (normally diphenyleneiodonium and/or apocynin) and new small NADPH oxidase inhibitors have been reported to clarify their potential value as NADPH oxidase inhibitors, selectivity versus other sources of ROS, and inherent ROS scavenger properties. ${ }^{193}$

\section{Peptide inhibitors}

In an attempt to eliminate off-target effects and gain selectivity for some NOX isoforms, the focus has been shifted on some occasions to the development of peptide inhibitors, which truly inhibit activation of NADPH oxidase. A more detailed review of these peptides has been published recently by El-Benna et al. ${ }^{205}$ Nox2ds-tat, a cell-permeative chimeric form targeting the assembly of NOX2, is a peptide inhibitor that binds to the p47phox subunit and prevents its interaction with other NADPH oxidase subunits. ${ }^{206}$ Therefore, it inhibits the NOX1 and NOX2 isoforms, but not NOX4, because this subunit is p47phox-independent. It decreased superoxide production and inhibited angiotensin II-induced blood pressure increases in animal models. ${ }^{103}$ Nox2ds, a nonchimeric peptide that mimics a sequence in the cytosolic 
B-loop of NOX2, was shown to inhibit superoxide anion production by the NOX2 isoform but not ROS production by NOX1 oxidase or NOX4 oxidase. ${ }^{207}$ Other peptide inhibitors were derived from $\mathrm{p} 22 \mathrm{phox}, \mathrm{p} 47 \mathrm{phox}$, or Rac1 subunits to prevent their phosphorylation, activation, or assembly to form the final enzyme complex. ${ }^{205}$ The proline-argininerich peptide, PR39 protein, is an inhibitor not derived from NADPH oxidase components that binds to the Src-homology region 3 (SH3) domain of p47phox subunits, limiting its regulatory activity. ${ }^{208}$ However, in terms of its mechanism of action, PR39 is not completely selective for NADPH oxidase and can affect any other protein possessing the SH3 domain. All these peptide inhibitors have shown low stability and lack of oral availability, making them clinically unattractive.

\section{Naturally occurring antioxidants}

The search for novel and specific NADPH oxidase inhibitors continues, and naturally occurring antioxidants represent another possible approach. In addition to apocynin, the best studied molecule of this origin, other natural components have NADPH oxidase inhibition properties. It has been found that polyphenols, apart from their well known superoxide radical scavenging ability, also decrease the activity of NADPH oxidase. ${ }^{209}$ In fact, the beneficial effects on cardiovascular disease may partly explain the protective role of polyphenolcontaining foods and beverages such as fruit, vegetables, green tea, and red wine. ${ }^{210-214}$ It should be kept in mind that designing antioxidant strategies with this type of polyphenol or other natural compounds requires additional randomized studies with dietary interventions.

According to the criteria suggested by Jaquet et al ${ }^{177}$ for defining new NADPH oxidase inhibitors, procyanidinrich fractions from distilled grape pomace should contain such type of drugs. Procyanidins from this origin, which are polyphenol compounds of the flavonoid group, inhibit NADPH oxidase activity in endothelial cells and cell disrupted systems. They also exerted inhibition at lower concentrations than those needed to scavenge superoxide anions in a cell-free in vitro system. ${ }^{215}$ Therefore, natural procyanidins from grapes seem to be a new source of NADPH oxidase inhibitors.

Other natural products have been shown to inhibit NADPH oxidase activity or prevent overexpression of some of its subunits in in vitro cell models under certain conditions.

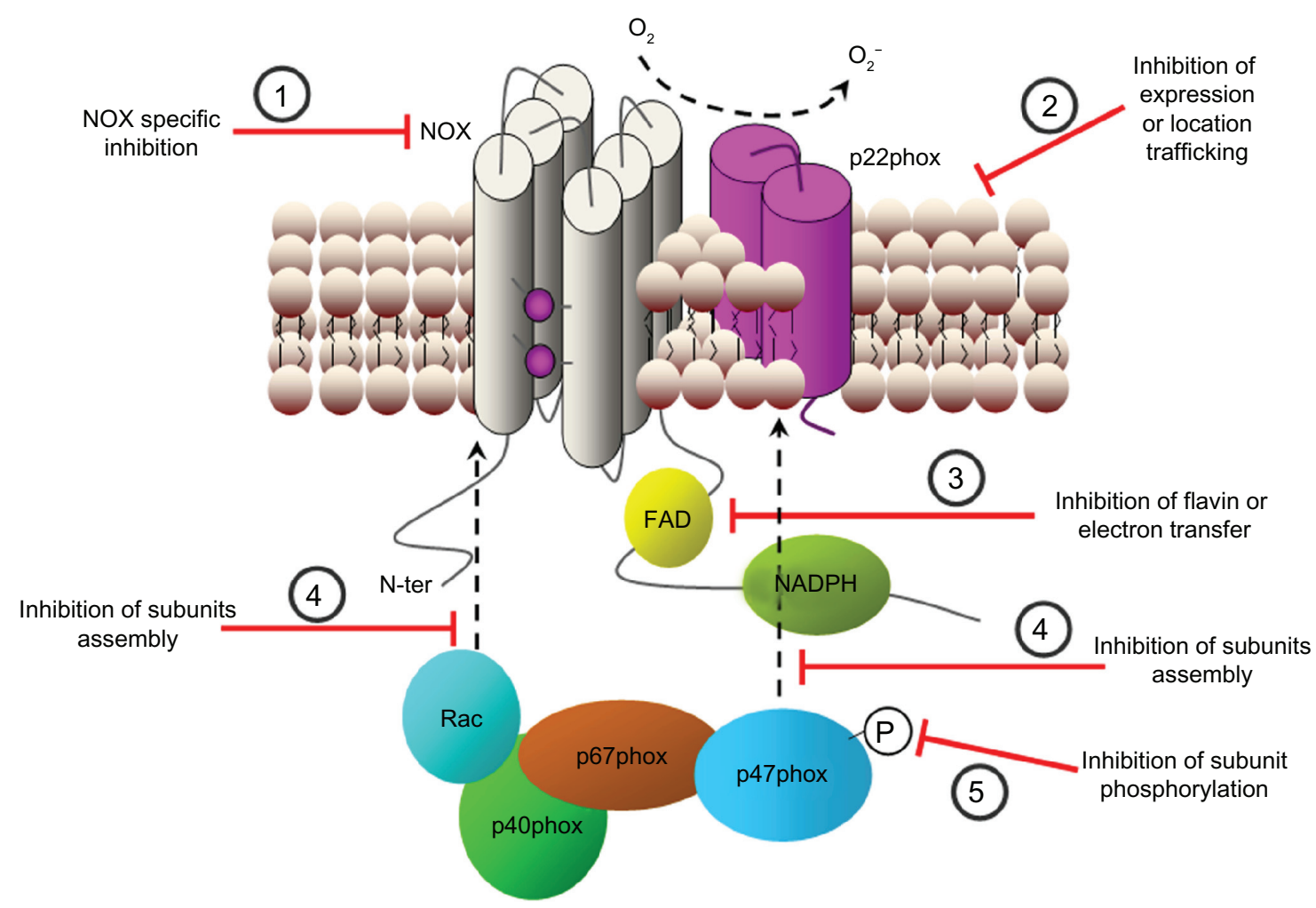

Figure 5 Sites for direct NADPH oxidase inhibition. Some mechanisms of action have been reported for NADPH oxidase inhibitors. (I) Specific inhibition of the catalytic subunit (NOX). (2) Inhibition of the expression of any subunit or inhibition of the traffic for subcellular location. (3) Flavin (cofactor) inhibition or electron transfer inhibition. (4) Inhibition of correct subunits assembly. (5) Inhibition of subunit phosphorylation (P) and activation.

Abbreviations: FAD, flavin adenine dinucleotide; $\mathrm{NADPH}$, reduced nicotinamide adenine dinucleotide phosphate; $\mathrm{N}$-ter, amino terminal; $\mathrm{O}_{2}$, superoxide anion. 
Flavonoids from Inula Britannica L reduced p47phox expression and phosphorylation in vascular smooth muscle cells, with a subsequent reduction in production of superoxide anions. ${ }^{168}$ Ginkgolide B, from the ginkgo biloba tree, attenuated the enhancement of NOX4 expression and ROS generation in human endothelial cells treated with oxidized low-density lipoprotein. ${ }^{170}$ Rutaecarpine reversed the NADPH oxidase activity induced by hypoxia-reoxygenation and upregulation of NOX2, NOX4, and p47phox in myocardial cells in vitro. ${ }^{171}$ Reinioside $\mathrm{C}$, a major compound of Polygala fallax $\mathrm{H}$, attenuated the upregulation of NADPH oxidase (NOX2 and p22phox) induced by oxidized low-density lipoprotein, generation of ROS, and activation of NF- $\kappa \mathrm{B}$ in endothelial cells. ${ }^{172}$ Resveratrol, a stilbene found in grapes and wine, and without superoxide scavenger properties, has been shown to inhibit NADPH oxidase activity in vascular tissues. $^{216}$ It also downregulated NOX4 and upregulated superoxide dismutase- 1 and glutathione peroxidase 1 (antioxidative enzymes) in a model of human endothelial cells. ${ }^{163}$ Therefore, resveratrol modifies the expression profile of pro-oxidative and antioxidative enzymes which could contribute to its vascular protective effect. Quercetin and its methylated metabolite, isorhamnetin, reduced endothelin 1-induced upregulation of the p47phox subunit and endothelial nitric oxide synthase uncoupling in the endothelium, but it is not clear if this is a direct or a protein kinase C-mediated mechanism. ${ }^{173}$

Studies in animal models under pathophysiologic conditions have also shown the inhibitory activity of some of these compounds. Epicatechin reduced the increased NADPH oxidase activity and overexpression of p47phox and p22phox in DOCA salt animals ${ }^{167}$ and rats after chronic inhibition of nitric oxide synthesis. ${ }^{217}$ Tanshinone IIA, a major constituent of Salvia miltiorrhiza B, inhibited increased NADPH oxidase activity and expression as well as superoxide anion production in a hypertensive rat model. ${ }^{169}$ Folic acid supplementation in the diet attenuated NADPH oxidase and xanthine oxidase activity and restored superoxide dismutase activity in the kidney of the hyperhomocysteinemic rat. ${ }^{218}$

Magnolol and honokiol are active components of Magnolia officinalis that inhibit NADPH oxidase activity, ${ }^{219}$ which explains some of their antioxidative and anti-inflammatory effects. ${ }^{220}$ Honokiol has been shown to reduce myocardial infarct size and cardiac arrhythmias in rats. ${ }^{221,222}$ This compound also suppresses apoptosis in high glucose-induced human endothelial cells via NADPH oxidase inhibition. ${ }^{223}$ Interestingly, this compound is able to inhibit NADPH oxidase after the enzyme is activated, but not before, which could be useful in pathologic conditions. In some cases, the natural product does not directly inhibit NADPH oxidase activity, but affects its regulation. Xuezhikang, an extract of red yeast rice, reduces NADPH oxidase activity by decreasing membrane translocation of its regulatory subunit $\mathrm{p} 47$ phox by inhibition of extracellular signal-regulated kinase $1 / 2$ activation. ${ }^{224}$

Puerarin, an isoflavone-C-glucoside, interferes with the NADPH oxidase-related ROS pathways and blocks NF- $\kappa B$ activation by inhibiting phosphorylation of $\mathrm{p} 47$ phox and Rac1.225 Tripterygium wilfordii Hook $\mathrm{F}$ is a traditional Chinese medicinal plant that contains some compounds with inhibitory effects on NADPH oxidase activity. One of these compounds is tripterine, which prevents Janus kinasedependent activation of inducible nitric oxide synthase and NOX1, an effect that consequently protects endothelial barrier function. ${ }^{226}$ Celastrol, another compound of the same plant, was demonstrated to be a potent nonspecific inhibitor of NOX1, NOX2, NOX4, and NOX5, with increased potency against NOX1 and NOX2.227 The suggested mechanism for this action is inhibition of the functional association between cytosolic subunits and the membrane enzyme complex.

\section{Pharmacophore models}

In cell systems overexpressing NOX4, several NOX4 oxidase inhibitors have been identified from compounds containing one of the following five core structures: oxalyl hydrazides, flavonoids, oxindoles, benzoquinolines, and benzothiophenes. ${ }^{228}$ From these data, the authors mapped the common pharmacophore points and constructed a pharmacophore model of a NOX4 oxidase inhibitor that comprised two hydrogen bond donors and acceptors and two aromatic-hydrophobic rings. ${ }^{228}$ Similarly, structure-activity relationship investigations around the pyrazolopyridine dione core and high-throughput screening led to the discovery of new inhibitors selective for NOX4 and NOX1 isoforms and with little affinity for the NOX2 isoform. ${ }^{196}$ Additionally, they showed good oral bioavailability. Independent of NOX isoform specificity, many NADPH oxidase inhibitors show some common structural features, ie, they are generally flat and lipophilic aromatic heterocyclic compounds. Further work is needed to determine the isoform selectivity of compound bases in pharmacophore models as well as their specificity for inhibition of ROS production via NADPH oxidases versus other sources.

\section{Novel perspectives}

It has been discovered recently that zinc signals have an essential role in the redox signaling network, and 
this implies that regulation of zinc homeostasis by zinc administration could be a novel strategic pharmacologic intervention for oxidative stress. In fact, intracellular zinc has a protective role in myocardial recovery from oxidative stress enhanced by ischemia-reperfusion injury. 229 Pyrithione, a zinc ionophore, reversed expression of NOX2 induced by hypoxia-reoxygenation and $\mathrm{p} 47 \mathrm{phox}$ phosphorylation in rat cardiac myocytes, indicating that this compound protects cardiomyocytes from reperfusion injury by attenuation of NADPH oxidase activity. ${ }^{230}$

A novel approach in the search for specific NADPH oxidase inhibitors has been targeted to the binding of the proline-rich domain of $\mathrm{p} 22 \mathrm{phox}$ to $\mathrm{p} 4 \mathrm{phox}$, a prerequisite for activation of some NADPH oxidase isoforms, ie, NOX1 and NOX2. A high-throughput screen monitoring this interaction identified ebselen, a glutathione peroxidase mimetic and hydrogen peroxide scavenger, and several of its analogs as potent inhibitors of this binding. ${ }^{231}$ This finding led to the proposal of ebselen as a new anti-inflammatory drug in view of its antioxidant properties. ${ }^{232}$ Naturally occurring products like celastrol have also been shown to disrupt binding of the proline-rich region of p22phox to the tandem SH3 domain of p47phox and NOX organizer 1 (NOXO1), the p47phox homologous. Naloxone, an opioid antagonist, has recently been shown to bind to NOX2 and inhibit both its action, and translocation of the $\mathrm{p} 47 \mathrm{phox}$ subunit to the membrane. ${ }^{233}$ This suggests a new mechanism of nonopioid action of naloxone, which has been suggested to be useful in the prevention of inflammation-mediated neurodegeneration.

\section{Modulation of signal transduction upstream of NADPH oxidase activation}

In addition to direct inhibition of NADPH oxidase, some drugs have the ability to regulate signaling pathways that participate in activation of NADPH oxidase activity. The main mechanisms involved in this effect are inhibition of the regulating NADPH oxidase subunits, by reduction of their phosphorylation or by blocking their translocation to the membrane complex of the enzyme, or reduction of the expression of one or more NADPH oxidase subunits (Figure 6). Interestingly, some drugs with this ability are commonly used in cardiovascular disease. Therefore, it is reasonable to think that, in addition to the primary mechanisms of action of these drugs, regulation of NADPH oxidase activity at the vascular level could also contribute to their beneficial effects.

\section{Blockade of the renin-angiotensin- aldosterone system}

The renin-angiotensin-aldosterone system is well characterized as being critically involved in cardiovascular disease. Its participation in the regulation of NADPH

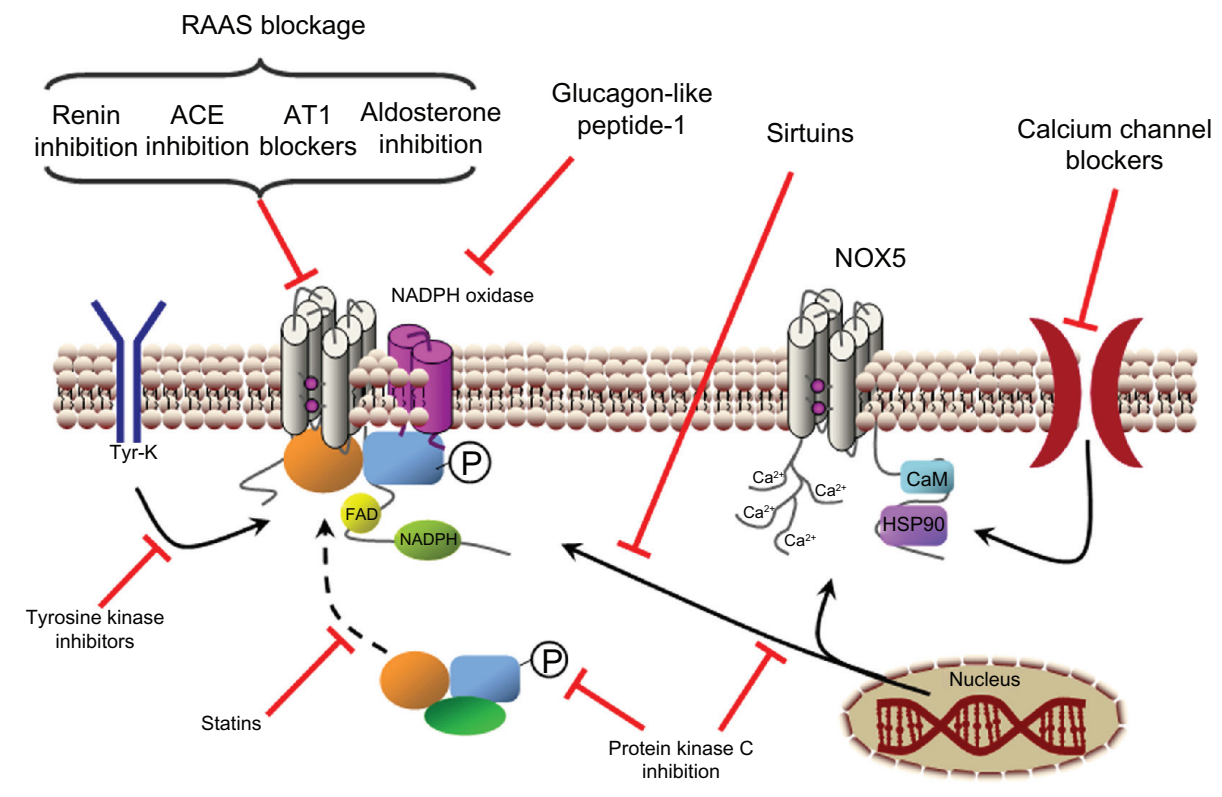

Figure 6 Indirect inhibition of NADPH oxidase. Points for NADPH oxidase activity inhibition or reduction of the enzyme's expression. The stimulating effects of the renin-angiotensin-aldosterone system (RAAS) on NADPH oxidase activity can be stopped by the inhibition of renin, angiotensin converting enzyme (ACE) or blockage of angiotensin II receptor I (ATI) or aldosterone receptor. Protein kinase C inhibition reduces NADPH oxidase phosphorylation (P) and expression. Glucagon-like peptide-I and tyrosine kinase inhibition reduce the activity and the expression of NADPH oxidases. Sirtuins reduce NOXI expression, whereas calcium channel blockers reduce NOX5 activity and statins decrease cytosolic subunit translocation to the membrane-fixed enzyme complex.

Abbreviations: $\mathrm{Ca}^{2+}$, calcium ion; CaM, calmodulin; FAD, flavin adenine dinucleotide; HSP90, heat shock protein 90; NADPH, reduced nicotinamide adenine dinucleotide phosphate; Tyr-K, tyrosine kinase. 
oxidase function has been demonstrated. ${ }^{234,235}$ Therefore, activation of NADPH oxidase is interrupted by inhibition of the renin-angiotensin-aldosterone system at any level, ie, renin inhibition, angiotensin-converting enzyme inhibition, angiotensin II blockade, or mineralocorticoid receptor blockade. Angiotensin-converting enzyme inhibitors affect several mechanisms of NADPH oxidase activity, including expression of the subunits, enzyme activation, and even AT1 receptor levels in animal models of cardiovascular disease or nephropathy. ${ }^{236-238}$ The effects of angiotensin II receptor antagonists on NADPH oxidase are superior to those exerted by angiotensin-converting enzyme inhibitors. ${ }^{239}$ Blockade of the AT1 receptor causes inhibition of NADPH oxidase and a decrease in superoxide anion production with noticeable improvement of endothelial function. ${ }^{234,240}$ Hence, AT1 receptor blockers can be considered as one of the most potent drugs clinically available for inhibiting activation of NADPH oxidase in the cardiovascular system.

Aliskiren, a new direct renin inhibitor, reduced vascular NADPH oxidase activity and atherosclerotic plaque in apolipoprotein E-deficient mice. ${ }^{241}$ However, neither aliskiren alone nor the combination of aliskiren and valsartan resulted in a greater reduction in myocardial fibrosis or hypertrophy or markers of oxidative stress in a transgenic model of tissue renin overexpression. ${ }^{242}$

Mineralocorticoid receptor activation by aldosterone includes mechanisms by which cardiomyocytes trigger NOX-dependent and reactive oxygen species-mediated coronary endothelial dysfunction. ${ }^{243}$ Expression of NOX isoforms like NOX1 can be also regulated by aldosterone in vascular tissue. ${ }^{244}$ Concordantly, use of eplerenone to antagonize mineralocorticoid receptors improved endothelial dysfunction and inhibited NADPH oxidase subunits in the post-myocardial infarction phase. ${ }^{245}$ In summary, inhibition of the renin-angiotensin-aldosterone system is a promising mechanism for regulation of NADPH oxidase in cardiovascular disease, and should be investigated further in clinical trials.

\section{Statins}

Statins, also known as 3-hydroxy-3-methylglutaryl-coenzyme A (HMG-CoA) reductase inhibitors, aid in the prevention of endothelial dysfunction by lowering low-density lipoprotein cholesterol levels and enhancing nitric oxide-dependent vasodilatation. ${ }^{246}$ Increasing evidence suggests that, at the same time, the pleiotropic effects of statins involve direct reduction of oxidative stress in blood vessels. Statins reduce both activity and expression of NOX1247 and NOX2 $2^{248}$ and the activity of NOX4 in endothelial cells. ${ }^{39}$ Therefore, several NOX isoforms may be affected. The effects of statins on activation of NADPH oxidase have been associated with inhibition of the geranylgeranylation of Rac1-GTPase (a regulatory subunit of NADPH oxidase complex), which is a required condition for Rac1 activation. ${ }^{247,249}$ However, this mechanism could explain the inhibition of Rac1 translocation but not the changes in expression of NOX isoforms and some NADPH oxidase subunits observed with statins. In fact, the mechanisms of action seem to differ from one vascular cell type to another, and there are conflicting data about the NADPH oxidase subunit implicated in each case. ${ }^{250}$ Atorvastatin, simvastatin, rosuvastatin, and fluvastatin have been shown to inhibit NADPH oxidase activity and expression of at least the p22phox and NOX1 isoforms. ${ }^{248}$ Moreover, the inhibitory effects of pitavastatin on NADPH oxidase activity have been shown to be independent of endothelial nitric oxide synthase, which was observed in mice deficient in this enzyme. ${ }^{251}$ Together, these data suggest that inhibition of NADPH oxidases may contribute to the beneficial cardiovascular effects of the statins, although relatively few human trials have been carried out to date and more specific biomarkers for the antioxidant effects of statins are needed to separate this action from their lipidlowering effects. ${ }^{252}$

\section{Calcium channel blockers}

The effects of calcium channel blockers have been studied in the context of NOX5, which is a calcium-dependent NADPH oxidase. Such phenomena link calcium to NOX5 signaling, which is potentially important in the regulation of endothelial function by angiotensin II and endothelin-1. ${ }^{253}$ However, because NOX5 is expressed predominantly in endothelial cells, concerns have been raised that the endothelium lacks the channels where calcium antagonists work. Amlodipine and manidipine reduced superoxide generation by inhibiting overexpression of NADPH oxidase in angiotensin II-stimulated rat endothelial cells. ${ }^{254}$ These effects may also lead to decreased expression of adhesion and chemoattractant molecules, thereby explaining the antiatherosclerotic effects of calcium channel blockers. ${ }^{255-257}$

\section{Protein kinase $\mathrm{C}$ inhibitors}

Several studies have demonstrated that protein kinase $\mathrm{C}$ is a strong NADPH oxidase activator, ${ }^{258}$ because this kinase phosphorylates NOX2 $2^{259}$ and even NOX5, elevating the calcium sensitivity of this isoform. ${ }^{260}$ However, protein kinase $\mathrm{C}$ participates in the signaling pathways of 
important stimuli for endothelial cells, such as TNF- $\alpha,{ }^{258,261}$ angiotensin II, ${ }^{262}$ and low-density lipoprotein cholesterol. ${ }^{263}$ Clinical studies have related the inhibition of protein kinase $\mathrm{C}$ to a decrease in superoxide anion generation and decreased hyperglycemia-induced endothelial dysfunction. ${ }^{264}$ However, the difficulty in translating this knowledge to clinical practice lies in the divergent and different roles of protein kinase $\mathrm{C}$ in the regulation of several cellular functions and their differences between distinct cell types.

\section{Tyrosine kinase inhibitors}

Tyrosine kinase inhibitors (tyrphostins) participate in regulation of NADPH oxidase activity and expression. Tyrphostin AG490 reduced the increased NADPH oxidase activity and expression of NOX1, NOX2, and NOX4 isoforms in apolipoprotein E-deficient mice. ${ }^{265}$ This effect ran parallel to a marked reduction in atherosclerotic lesions of the aorta. In vascular tissue, the main target for the NADPH oxidase inhibitory effect of tyrphostins could be the EGFR kinase. This enzyme has been related to activation of NADPH oxidase in vascular tissue, and tyrosine kinase inhibition has been associated with restoration of impaired endotheliumdependent relaxation, ${ }^{102}$ inhibition of angiotensin II-induced and pyrogallol-induced potentiation of contraction, ${ }^{266}$ and even reduction of NOX2 and NOX4 overexpression. ${ }^{267}$ Together, these results implicate EGFR kinase and NADPH oxidase activation downstream in endothelial dysfunction.

\section{Sirtuins}

A relationship has been shown recently between sirtuin 1, a nicotinamide adenine dinucleotide-dependent deacetylase, and NADPH oxidases, more specifically with the NOX1 isoform. ${ }^{268}$ Sirtuin 1 exerts protective effects in atherosclerosis by promoting endothelium-dependent vascular relaxation. In vascular smooth muscle cells, overexpression of sirtuin 1 significantly inhibited angiotensin II-induced hypertrophy, while knockdown of sirtuin-1 resulted in increased growth of vascular smooth muscle cells. Expression of NOX1 induced by angiotensin II was inhibited by sirtuin 1 in these cells, whereas sirtuin 1 inhibition increased NOX1 expression. ${ }^{269}$

In isolated aorta from Wistar rats, inhibition of sirtuin 1 significantly increased vascular superoxide production and enhanced NADPH oxidase activity and expression of p22phox and NOX4 subunits, together contributing to endothelial dysfunction, as evidenced by reduced relaxation in response to endothelium-dependent vasodilators. $^{270}$

\section{Glucagon-like peptide- I}

Glucagon-like peptide-1, one of the incretin hormones, has been reported to have beneficial cardiovascular effects. At least part of these effects has been related to antioxidant properties via NADPH oxidases. Glucagon-like peptide-1 decreased high-glucose-induced ROS production, as well as levels of NADPH oxidase subunits, such as p47phox and NOX2, in microvascular cardiac endothelial cells from rats. ${ }^{271}$ In human umbilical vein endothelial cells, liraglutide, a glucagon-like peptide-1 analog, significantly decreased TNF$\alpha$-induced ROS production and overexpression of NOX 2 and p22phox. ${ }^{272}$ Together, these results suggest that the glucagonlike peptide-1 signaling pathway is another interesting point to target for reduction of NADPH oxidase activity.

\section{Perspectives}

The NOX1 and NOX2 isoforms currently appear to be the major contributors to oxidative stress in cardiovascular disease, so are the most logical therapeutic targets. However, none of the NADPH oxidase inhibitors found or developed thus far show selectivity for these isoforms. Taking into account that the other NADPH oxidase isoforms have important roles in some processes, inhibitors displaying a dual selectivity for NOX1 and NOX2 or for NOX2 and NOX4 over other NADPH oxidases will probably offer great benefits in terms of therapeutic efficacy versus side effects. In this way, some authors have postulated rational approaches to identify new target sites for novel dual inhibitors of vascular NOX1 and NOX2 isoforms. ${ }^{27}$ The potential implications of inhibiting the important extravascular effects of NOX2 must be considered, given that its crucial role in the innate immune response will severely compromise immunologic function. This consideration will mandate dose titration of an NADPH oxidase inhibitor to partially inhibit the target NADPH oxidase in the vascular wall without affecting immune function.

\section{Assembly and activation of the NADPH oxidase complex}

Inhibiting formation of the NADPH oxidase complex is a known way of preventing activation of NADPH oxidase, particularly with the NOX1 and NOX2 isoforms. This approach has been most successful in inhibiting NOX2 because activation of this isoform depends on its association with the p47phox, p67phox, and p40phox cytosolic subunits. P47phox contains an autoinhibitory domain that prevents translocation of this subunit to the membrane NADPH oxidase subcomplex. Phosphorylation of $\mathrm{p} 47 \mathrm{phox}$ relieves 
this autoinhibition and allows translocation to form the final NADPH oxidase complex. ${ }^{273}$ NOX1 does not necessarily rely on complex assembly for activation because it can associate with NOXO1, the p47phox homologous, which does not have an autoinhibitory domain. ${ }^{274}$ NOX4 and NOX5 do not use cytosolic subunits, so do not rely on complex assembly for activation.

Several drugs interfere with assembly of the NADPH oxidase complex as discussed above. AEBSF, apocynin, phenylarsine oxide, gliotoxin, and Nox2ds-tat prevent binding of $\mathrm{p} 47$ phox to the membrane complex. Ebselen and celastrol block the union between p22phox and p47phox. A particular mechanism to inhibit complex formation is that used by the statins, which inhibit geranylgeranylation of Rac1, thereby preventing translocation and activation of the NADPH oxidase complex.

\section{Specific inhibitors of phosphorylation}

Phosphorylation is an important mechanism in regulating assembly and activation of the NADPH oxidase complex. ${ }^{275}$ As mentioned above, p47phox must be phosphorylated in order to translocate and bind to the NADPH oxidase membrane complex. Phosphorylation of $\mathrm{NOX} 2^{259}$ or NOX $5^{260}$ by protein kinase $\mathrm{C}$ enhances its assembly or sensitivity to activation, respectively. Therefore, approaches to prevent specific subunit phosphorylation would be another useful strategy to inhibit some specific NADPH oxidase isoforms.

\section{Calcium dependence of NOX5}

The calcium dependence of the NOX5 isoform offers a unique point of action with therapeutic utility. Inhibition of calcium release is expected to interfere with NOX5 signaling, which could be important with regard to responses of endothelial cells to relevant stimuli at the endothelium, such as angiotensin II or endothelin 1.253 This observation could explain the observation that calcium channel blockers potentiate the protective effects of angiotensin II receptor blockers on vascular endothelium in the rat. ${ }^{276}$

\section{Optimization of electron transfer inhibition by NADPH oxidase}

NADPH oxidase inhibitors like diphenyleneiodonium block generation of ROS by preventing electron flow through the enzyme, so oxygen does not receive the electrons and ROS production is stopped. However, the activity of diphenyleneiodonium is nonspecific for other electron-transporting enzymes. Therefore, it will be interesting to develop an electron extractor capable of binding specifically to a particular NOX isoform. Another approach to interfering with electron transfer is anion channel inhibition because transfer of electrons across the membrane where NADPH oxidase is fixed is electrogenic and requires charge compensation through anion channels, such as chloride-proton antiporter ClC-3.277,278 Therefore, specific inhibitors of $\mathrm{ClC}-3$ or similarly relevant antiporters may be an effective strategy to reduce NOX-mediated cardiovascular disease.

\section{Reaching the target}

Due to the specific pattern of expression of each NOX isoform in tissues and in each type of cell and because of the specific subcellular location of each NOX isoform, therapeutic targeting to the correct NADPH oxidase in its appropriate localization is not a banal question. In this sense, localization motifs in protein sequences provide an attractive therapeutic target for new NADPH oxidase inhibitors. However, additional studies identifying and characterizing NOX trafficking motifs and the adaptor proteins interacting with them are needed. A related question, which supposes an important limitation of antioxidant therapy, is the potential disruption of physiologic ROS-dependent cell signaling or the intracellular redox state. Therefore, creating antioxidants that target cellular microdomains containing NOX may be a solution to this limitation.

\section{Controversies}

One important question arises from the recent findings about the hypothetical beneficial role of NOX4. Mice deficient in this isoform show reduced expression of endothelial nitric oxide synthase and heme oxygenase-1 (the vascular source of nitric oxide and carbon monoxide, respectively), both of which are known for their protective vascular roles. ${ }^{279}$ On the contrary, overexpression of NOX4 enhances vasodilatation induced by acetylcholine or histamine, which explains the lower systemic blood pressure found in these animals. ${ }^{280}$ Moreover, NOX4 seems to produce hydrogen peroxide indirectly ${ }^{54}$ or directly, ${ }^{55}$ although the exact mechanism for formation of hydrogen peroxide is not clear. Together, these results confirm the need for further investigations of the role of the specific contribution of each NADPH oxidase isoform in physiologic and pathophysiologic cardiovascular signaling.

\section{Conclusion}

The role of NADPH oxidases in cardiovascular disease has been confirmed. The combination of each NOX isoform and its 
particular cellular and subcellular locations may determine the specific signaling pathway where NADPH oxidases participate. However, further investigation is needed to clarify this issue in order to define the ideal target for NADPH oxidase inhibition. Regarding the method of inhibiting NADPH oxidase, NOX specificity is the focus of current investigations. Some inhibitors as well as direct and indirect approaches are available, as discussed above. Studies of the chemical structure-activity relationship for known inhibitors have provided pharmacophore models to assist in the search for new molecules. Likewise, some of the old and newer approaches include inhibition of assembly of the NADPH oxidase complex, subcellular translocation, post-transductional modifications, calcium entry/ release, and electron transfer. High-throughput screens for any of these activities could provide new inhibitors. From a general point of view, small-molecule inhibitors are preferred because of their hydrosolubility and oral bioavailability. However, other possibilities are not closed, with peptide inhibitors and monoclonal antibodies against NOX isoforms continuing to be under investigation, as well as a search for naturally occurring compounds. We are confident that, in the next few years, all this knowledge and research in progress will likely result in the development of new drugs for inhibition of NADPH oxidase and novel therapeutic approaches to the treatment of cardiovascular disease.

\section{Acknowledgments}

This study was supported in part by the Plan Nacional Español de I+D, 2008-2011, and the Instituto de Salud Carlos III, Subdirección General de Evaluación y Fomento de la Investigación (PI10/01403) cofinanced by European Regional Development Fund. The Isidro Parga Pondal program of the Xunta de Galicia supported the work of EÁ. The work of BP-D is supported by the Instituto de Salud Carlos III (FI11/00325).

\section{Disclosure}

The authors report no conflicts of interest in this work.

\section{References}

1. Myung SK, Ju W, Cho B, et al; Korean Meta-Analysis Study Group. Efficacy of vitamin and antioxidant supplements in prevention of cardiovascular disease: systematic review and meta-analysis of randomised controlled trials. BMJ. 2013;346:f10.

2. Griendling KK, Sorescu D, Ushio-Fukai M. NAD(P)H oxidase: role in cardiovascular biology and disease. Circ Res. 2000;86(5); 494-501.

3. Cai H, Harrison DG. Endothelial dysfunction in cardiovascular diseases: the role of oxidant stress. Circ Res. 2000;87(10):840-844.

4. Gao L, Mann GE. Vascular NAD(P)H oxidase activation in diabetes: a double-edged sword in redox signalling. Cardiovasc Res. 2009;82(1): 9-20.
5. Montezano AC, Touyz RM. Reactive oxygen species and endothelial function - role of nitric oxide synthase uncoupling and Nox family nicotinamide adenine dinucleotide phosphate oxidases. Basic Clin Pharmacol Toxicol. 2012;110(1):87-94.

6. Okamoto A, Iwamoto Y, Maru Y. Oxidative stress-responsive transcription factor ATF3 potentially mediates diabetic angiopathy. Mol Cell Biol. 2006;26(3):1087-1097.

7. Lin SJ, Shyue SK, Hung YY, et al. Superoxide dismutase inhibits the expression of vascular cell adhesion molecule-1 and intracellular cell adhesion molecule-1 induced by tumor necrosis factor-alpha in human endothelial cells through the JNK/p38 pathways. Arterioscler Thromb Vasc Biol. 2005;25(2):334-340.

8. Warabi E, Takabe W, Minami T, et al. Shear stress stabilizes NF-E2related factor 2 and induces antioxidant genes in endothelial cells: role of reactive oxygen/nitrogen species. Free Radic Biol Med. 2007;42(2): 260-269.

9. Chen XL, Zhang Q, Zhao R, Ding X, Tummala PE, Medford RM. Rac1 and superoxide are required for the expression of cell adhesion molecules induced by tumor necrosis factor-alpha in endothelial cells. J Pharmacol Exp Ther. 2003;305(2):573-580.

10. True AL, Rahman A, Malik AB. Activation of NF-kappaB induced by H(2) $\mathrm{O}(2)$ and TNF-alpha and its effects on ICAM-1 expression in endothelial cells. Am J Physiol Lung Cell Mol Physiol. 2000;279(2):L302-L311.

11. Wolfram Kuhlmann CR, Wiebke Ludders D, Schaefer CA, et al. Lysophosphatidylcholine-induced modulation of $\mathrm{Ca}(2+)$-activated $\mathrm{K}(+)$ channels contributes to ROS-dependent proliferation of cultured human endothelial cells. J Mol Cell Cardiol. 2004;36(5):675-682.

12. Abid MR, Kachra Z, Spokes KC, Aird WC. NADPH oxidase activity is required for endothelial cell proliferation and migration. FEBS Lett. 2000;486(3):252-256.

13. Moldovan L, Mythreye K, Goldschmidt-Clermont PJ, Satterwhite LL. Reactive oxygen species in vascular endothelial cell motility. Roles of NAD(P)H oxidase and Rac1. Cardiovasc Res. 2006;71(2): 236-246.

14. Eyries M, Collins T, Khachigian LM. Modulation of growth factor gene expression in vascular cells by oxidative stress. Endothelium. 2004;11(2):133-139.

15. Hu T, Ramachandrarao SP, Siva S, et al. Reactive oxygen species production via NADPH oxidase mediates TGF-beta-induced cytoskeletal alterations in endothelial cells. Am J Physiol Renal Physiol. 2005;289(4):F816-F825.

16. Hu Q, Zheng G, Zweier JL, Deshpande S, Irani K, Ziegelstein RC. NADPH oxidase activation increases the sensitivity of intracellular $\mathrm{Ca} 2+$ stores to inositol 1,4,5-trisphosphate in human endothelial cells. J Biol Chem. 2000;275(21):15749-15757.

17. Miller AA, Drummond GR, Sobey CG. Novel isoforms of NADPHoxidase in cerebral vascular control. Pharmacol Ther. 2006;111(3): 928-948.

18. Widder JD, Harrison DG. Can vitamin E prevent cardiovascular events and cancer? Nat Clin Pract Cardiovasc Med. 2005;2(10): $510-511$.

19. Brieger K, Schiavone S, Miller FJ Jr, Krause KH. Reactive oxygen species: from health to disease. Swiss Med Wkly. 2012;142w13659.

20. Leto TL, Morand S, Hurt D, Ueyama T. Targeting and regulation of reactive oxygen species generation by Nox family NADPH oxidases. Antioxid Redox Signal. 2009;11(10):2607-2619.

21. Cosentino F, Francia P, Camici GG, Pelicci PG, Lüscher TF, Volpe M. Final common molecular pathways of aging and cardiovascular disease: role of the p66Shc protein. Arterioscler Thromb Vasc Biol. 2008;28(4): 622-628.

22. Cruzado MC, Risler NR, Miatello RM, Yao G, Schiffrin EL, Touyz RM. Vascular smooth muscle cell $\mathrm{NAD}(\mathrm{P}) \mathrm{H}$ oxidase activity during the development of hypertension: effect of angiotensin II and role of insulinlike growth factor-1 receptor transactivation. Am J Hypertens. 2005;18(1):81-87.

23. Schramm A, Matusik P, Osmenda G, Guzik TJ. Targeting NADPH oxidases in vascular pharmacology. Vascul Pharmacol. 2012;56(5-6):216-231. 
24. Doughan AK, Harrison DG, Dikalov SI. Molecular mechanisms of angiotensin II-mediated mitochondrial dysfunction: linking mitochondrial oxidative damage and vascular endothelial dysfunction. Circ Res. 2008;102(4):488-496.

25. Ray R, Shah AM. NADPH oxidase and endothelial cell function. Clin Sci (Lond). 2005;109(3):217-226.

26. Guzik TJ, West NE, Black E, et al. Vascular superoxide production by $\mathrm{NAD}(\mathrm{P}) \mathrm{H}$ oxidase: association with endothelial dysfunction and clinical risk factors. Circ Res. 2000;86(9):E85-E90.

27. Drummond GR, Selemidis S, Griendling KK, Sobey CG. Combating oxidative stress in vascular disease: NADPH oxidases as therapeutic targets. Nat Rev Drug Discov. 2011;10(6):453-471.

28. Takac I, Schroder K, Brandes RP. The Nox family of NADPH oxidases: friend or foe of the vascular system? Curr Hypertens Rep. 2012;14(1):70-78.

29. Altenhofer S, Kleikers PW, Radermacher KA, et al. The NOX toolbox: validating the role of NADPH oxidases in physiology and disease. Cell Mol Life Sci. 2012;69(14):2327-2343.

30. Brandes RP, Schroder K. Composition and functions of vascular nicotinamide adenine dinucleotide phosphate oxidases. Trends Cardiovasc Med. 2008;18(1):15-19.

31. Bengtsson SH, Gulluyan LM, Dusting GJ, Drummond GR. Novel isoforms of NADPH oxidase in vascular physiology and pathophysiology. Clin Exp Pharmacol Physiol. 2003;30(11):849-854.

32. Niu XL, Madamanchi NR, Vendrov AE, et al. Nox activator 1: a potential target for modulation of vascular reactive oxygen species in atherosclerotic arteries. Circulation. 2010;121(4):549-559.

33. Sheehan AL, Carrell S, Johnson B, Stanic B, Banfi B, Miller FJ Jr. Role for Nox1 NADPH oxidase in atherosclerosis. Atherosclerosis. 2011;216(2):321-326.

34. Douglas G, Bendall JK, Crabtree MJ, et al. Endothelial-specific Nox2 overexpression increases vascular superoxide and macrophage recruitment in ApoE-/- mice. Cardiovasc Res. 2012;94(1): 20-29.

35. Lyle AN, Deshpande NN, Taniyama Y, et al. Poldip2, a novel regulator of Nox 4 and cytoskeletal integrity in vascular smooth muscle cells. Circ Res. 2009;105(3):249-259.

36. Judkins CP, Diep H, Broughton BR, et al. Direct evidence of a role for Nox2 in superoxide production, reduced nitric oxide bioavailability, and early atherosclerotic plaque formation in ApoE-/- mice. Am J Physiol Heart Circ Physiol. 2010;298(1):H24-H32.

37. Ellmark SH, Dusting GJ, Fui MN, Guzzo-Pernell N, Drummond GR. The contribution of Nox4 to NADPH oxidase activity in mouse vascular smooth muscle. Cardiovasc Res. 2005;65(2):495-504.

38. Wind S, Beuerlein K, Armitage ME, et al. Oxidative stress and endothelial dysfunction in aortas of aged spontaneously hypertensive rats by NOX1/2 is reversed by NADPH oxidase inhibition. Hypertension. 2010;56(3):490-497.

39. Alvarez E, Rodino-Janeiro BK, Ucieda-Somoza R, GonzálezJuanatey JR. Pravastatin counteracts angiotensin II-induced upregulation and activation of NADPH oxidase at plasma membrane of human endothelial cells. J Cardiovasc Pharmacol. 2010;55(2): 203-212.

40. Basuroy S, Bhattacharya S, Leffler CW, Parfenova H. Nox4 NADPH oxidase mediates oxidative stress and apoptosis caused by TNF-alpha in cerebral vascular endothelial cells. Am J Physiol Cell Physiol. 2009;296(3):C422-C432.

41. Basuroy S, Tcheranova D, Bhattacharya S, Leffler CW, Parfenova H. Nox4 NADPH oxidase-derived reactive oxygen species, via endogenous carbon monoxide, promote survival of brain endothelial cells during TNF-alpha-induced apoptosis. Am J Physiol Cell Physiol. 2011;300(2): C256-C265.

42. Datla SR, Peshavariya H, Dusting GJ, Mahadev K, Goldstein BJ, Jiang F. Important role of Nox4 type NADPH oxidase in angiogenic responses in human microvascular endothelial cells in vitro. Arterioscler Thromb Vasc Biol. 2007;27(11):2319-2324.
43. Peshavariya H, Dusting GJ, Jiang F, et al. NADPH oxidase isoform selective regulation of endothelial cell proliferation and survival. Naunyn Schmiedebergs Arch Pharmacol. 2009;380(2):193-204.

44. Petry A, Djordjevic T, Weitnauer M, Kietzmann T, Hess J, Görlach A. NOX2 and NOX4 mediate proliferative response in endothelial cells. Antioxid Redox Signal. 2006;8(9-10):1473-1484.

45. Wu RF, Ma Z, Liu Z, Terada LS. Nox4-derived H2O2 mediates endoplasmic reticulum signaling through local Ras activation. Mol Cell Biol. 2010;30(14):3553-3568.

46. Gordillo G, Fang H, Park H, Roy S. Nox-4-dependent nuclear H2O2 drives DNA oxidation resulting in 8-OHdG as urinary biomarker and hemangioendothelioma formation. Antioxid Redox Signal. 2010;12(8): 933-943.

47. Pedruzzi E, Guichard C, Ollivier V, et al. NAD(P)H oxidase Nox-4 mediates 7-ketocholesterol-induced endoplasmic reticulum stress and apoptosis in human aortic smooth muscle cells. Mol Cell Biol. 2004;24(24):10703-10717.

48. Clempus RE, Sorescu D, Dikalova AE, et al. Nox 4 is required for maintenance of the differentiated vascular smooth muscle cell phenotype. Arterioscler Thromb Vasc Biol. 2007;27(1):42-48.

49. Szocs K, Lassegue B, Sorescu D, et al. Upregulation of Nox-based $\mathrm{NAD}(\mathrm{P}) \mathrm{H}$ oxidases in restenosis after carotid injury. Arterioscler Thromb Vasc Biol. 2002;22(1):21-27.

50. Ismail S, Sturrock A, Wu P, et al. NOX4 mediates hypoxia-induced proliferation of human pulmonary artery smooth muscle cells: the role of autocrine production of transforming growth factor- $\{$ beta $\} 1$ and insulin-like growth factor binding protein-3. Am J Physiol Lung Cell Mol Physiol. 2009;296(3):L489-L499.

51. Sturrock A, Huecksteadt TP, Norman K, et al. Nox4 mediates TGFbeta1-induced retinoblastoma protein phosphorylation, proliferation, and hypertrophy in human airway smooth muscle cells. Am J Physiol Lung Cell Mol Physiol. 2007;292(6):L1543-L1555.

52. Thomas SR, Witting PK, Drummond GR. Redox control of endothelial function and dysfunction: molecular mechanisms and therapeutic opportunities. Antioxid Redox Signal. 2008;10(10):1713-1765.

53. Dikalov SI, Dikalova AE, Bikineyeva AT, Schmidt HH, Harrison DG, Griendling KK. Distinct roles of Nox1 and Nox4 in basal and angiotensin II-stimulated superoxide and hydrogen peroxide production. Free Radic Biol Med. 2008;45(9):1340-1351.

54. Serrander L, Cartier L, Bedard K, et al. NOX4 activity is determined by mRNA levels and reveals a unique pattern of ROS generation. Biochem J. 2007;406(1):105-114.

55. Takac I, Schroder K, Zhang L, et al. The E-loop is involved in hydrogen peroxide formation by the NADPH oxidase Nox4. J Biol Chem. 2011;286(15):13304-13313.

56. BelAiba RS, Djordjevic T, Petry A, et al. NOX5 variants are functionally active in endothelial cells. Free Radic Biol Med. 2007;42(4): 446-459.

57. Jay DB, Papaharalambus CA, Seidel-Rogol B, et al. Nox5 mediates PDGF-induced proliferation in human aortic smooth muscle cells. Free Radic Biol Med. 2008;45(3):329-335.

58. Guzik TJ, Chen W, Gongora MC, et al. Calcium-dependent NOX5 nicotinamide adenine dinucleotide phosphate oxidase contributes to vascular oxidative stress in human coronary artery disease. $\mathrm{J} \mathrm{Am} \mathrm{Coll}$ Cardiol. 2008;52(22):1803-1809.

59. Loukogeorgakis SP, van den Berg MJ, Sofat R, et al. Role of NADPH oxidase in endothelial ischemia/reperfusion injury in humans. Circulation. 2010;121(21):2310-2316.

60. Bedard K, Krause KH. The NOX family of ROS-generating NADPH oxidases: physiology and pathophysiology. Physiol Rev. 2007;87(1): 245-313.

61. Girouard H, Wang G, Gallo EF, et al. NMDA receptor activation increases free radical production through nitric oxide and NOX2. J Neurosci. 2009;29(8):2545-2552.

62. Miller AA, Drummond GR, Schmidt HH, Sobey CG. NADPH oxidase activity and function are profoundly greater in cerebral versus systemic arteries. Circ Res. 2005;97(10):1055-1062. 
63. Jackman KA, Miller AA, De Silva TM, Crack PJ, Drummond GR, Sobey CG. Reduction of cerebral infarct volume by apocynin requires pretreatment and is absent in Nox2-deficient mice. Br J Pharmacol. 2009;156(4):680-688.

64. Kunz A, Anrather J, Zhou P, Orio M, Iadecola C. Cyclooxygenase-2 does not contribute to postischemic production of reactive oxygen species. J Cereb Blood Flow Metab. 2007;27(3):545-551.

65. Walder CE, Green SP, Darbonne WC, et al. Ischemic stroke injury is reduced in mice lacking a functional NADPH oxidase. Stroke. 1997; 28(11):2252-2258.

66. Brait VH, Jackman KA, Walduck AK, et al. Mechanisms contributing to cerebral infarct size after stroke: gender, reperfusion, T lymphocytes, and Nox2-derived superoxide. J Cereb Blood Flow Metab. 2010;30(7): 1306-1317.

67. Kahles T, Luedike P, Endres M, et al. NADPH oxidase plays a central role in blood-brain barrier damage in experimental stroke. Stroke. 2007;38(11):3000-3006.

68. Chen H, Song YS, Chan PH. Inhibition of NADPH oxidase is neuroprotective after ischemia-reperfusion. J Cereb Blood Flow Metab. 2009;29(7):1262-1272.

69. Kleinschnitz C, Grund H, Wingler K, et al. Post-stroke inhibition of induced NADPH oxidase type 4 prevents oxidative stress and neurodegeneration. PLoS Biol. 2010;8(9):pii e1000479.

70. Jackman KA, Miller AA, Drummond GR, Sobey CG. Importance of NOX1 for angiotensin II-induced cerebrovascular superoxide production and cortical infarct volume following ischemic stroke. Brain Res. 2009;1286:215-220.

71. Kahles T, Kohnen A, Heumueller S, et al. NADPH oxidase Nox1 contributes to ischemic injury in experimental stroke in mice. Neurobiol Dis. 2010;40(1):185-192.

72. Giordano FJ. Oxygen, oxidative stress, hypoxia, and heart failure. J Clin Invest. 2005;115(3):500-508.

73. Grote K, Flach I, Luchtefeld M, et al. Mechanical stretch enhances mRNA expression and proenzyme release of matrix metalloproteinase-2 (MMP-2) via NAD(P)H oxidase-derived reactive oxygen species. Circ Res. 2003;92(11):e80-e86.

74. Siwik DA, Pagano PJ, Colucci WS. Oxidative stress regulates collagen synthesis and matrix metalloproteinase activity in cardiac fibroblasts. Am J Physiol Cell Physiol. 2001;280(1):C53-C60.

75. Dhalla NS, Temsah RM, Netticadan T. Role of oxidative stress in cardiovascular diseases. J Hypertens. 2000;18(6):655-673.

76. Dhalla AK, Hill MF, Singal PK. Role of oxidative stress in transition of hypertrophy to heart failure. J Am Coll Cardiol. 1996;28(2):506-514.

77. Maytin M, Siwik DA, Ito M, et al. Pressure overload-induced myocardial hypertrophy in mice does not require gp91 phox. Circulation. 2004;109(9):1168-1171.

78. Bendall JK, Cave AC, Heymes C, Gall N, Shah AM. Pivotal role of a gp91(phox)-containing NADPH oxidase in angiotensin IIinduced cardiac hypertrophy in mice. Circulation. 2002;105(3): 293-296.

79. Byrne JA, Grieve DJ, Bendall JK, et al. Contrasting roles of NADPH oxidase isoforms in pressure-overload versus angiotensin II-induced cardiac hypertrophy. Circ Res. 2003;93(9):802-805.

80. Li JM, Gall NP, Grieve DJ, Chen M, Shah AM. Activation of NADPH oxidase during progression of cardiac hypertrophy to failure. Hypertension. 2002;40(4):477-484.

81. Kuroda J, Ago T, Matsushima S, Zhai P, Schneider MD, Sadoshima J. NADPH oxidase 4 (Nox4) is a major source of oxidative stress in the failing heart. Proc Natl Acad Sci U S A. 2010;107(35):15565-15570.

82. Zhang M, Brewer AC, Schroder K, et al. NADPH oxidase-4 mediates protection against chronic load-induced stress in mouse hearts by enhancing angiogenesis. Proc Natl Acad Sci U S A. 2010;107(42): 18121-18126.

83. Looi YH, Grieve DJ, Siva A, et al. Involvement of Nox2 NADPH oxidase in adverse cardiac remodeling after myocardial infarction. Hypertension. 2008;51(2):319-325.
84. Hoffmeyer MR, Jones SP, Ross CR, et al. Myocardial ischemia/reperfusion injury in NADPH oxidase-deficient mice. Circ Res. 2000; 87(9):812-817.

85. Doerries C, Grote K, Hilfiker-Kleiner D, et al. Critical role of the $\mathrm{NAD}(\mathrm{P}) \mathrm{H}$ oxidase subunit $\mathrm{p} 47 \mathrm{phox}$ for left ventricular remodeling/ dysfunction and survival after myocardial infarction. Circ Res. 2007; 100(6):894-903.

86. Wang JN, Shi N, Chen SY. Manganese superoxide dismutase inhibits neointima formation through attenuation of migration and proliferation of vascular smooth muscle cells. Free Radic Biol Med. 2012;52(1): 173-181.

87. Lassegue B, Griendling KK. NADPH oxidases: functions and pathologies in the vasculature. Arterioscler Thromb Vasc Biol. 2010;30(4):653-661

88. Akasaki T, Ohya Y, Kuroda J, et al. Increased expression of gp91phox homologues of $\mathrm{NAD}(\mathrm{P}) \mathrm{H}$ oxidase in the aortic media during chronic hypertension: involvement of the renin-angiotensin system. Hypertens Res. 2006;29(10):813-820.

89. Oelze M, Warnholtz A, Faulhaber J, et al. NADPH oxidase accounts for enhanced superoxide production and impaired endothelium-dependent smooth muscle relaxation in BKbeta1-/- mice. Arterioscler Thromb Vasc Biol. 2006;26(8):1753-1759.

90. Wang P, Tang F, Li R, et al. Contribution of different Nox homologues to cardiac remodeling in two-kidney two-clip renovascular hypertensive rats: effect of valsartan. Pharmacol Res. 2007;55(5):408-417.

91. Nakano D, Kurumazuka D, NagaiY, Nishiyama A, Kiso Y, Matsumura Y. Dietary sesamin suppresses aortic NADPH oxidase in DOCA salt hypertensive rats. Clin Exp Pharmacol Physiol. 2008;35(3):324-326.

92. Nakamura T, Yamamoto E, Kataoka K, et al. Beneficial effects of pioglitazone on hypertensive cardiovascular injury are enhanced by combination with candesartan. Hypertension. 2008;51(2):296-301.

93. Dikalova A, Clempus R, Lassegue B, et al. Nox1 overexpression potentiates angiotensin II-induced hypertension and vascular smooth muscle hypertrophy in transgenic mice. Circulation. 2005;112(17): 2668-2676.

94. Dikalova AE, Gongora MC, Harrison DG, Lambeth JD, Dikalov S, Griendling KK. Upregulation of Nox1 in vascular smooth muscle leads to impaired endothelium-dependent relaxation via eNOS uncoupling. Am J Physiol Heart Circ Physiol. 2010;299(3):H673-H679.

95. Gavazzi G, Banfi B, Deffert C, et al. Decreased blood pressure in NOX1-deficient mice. FEBS Lett. 2006;580(2):497-504.

96. Matsuno K, Yamada H, Iwata K, et al. Nox1 is involved in angiotensin II-mediated hypertension: a study in Nox1-deficient mice. Circulation. 2005;112(17):2677-2685.

97. Gavazzi G, Deffert C, Trocme C, Schäppi M, Herrmann FR, Krause KH. NOX1 deficiency protects from aortic dissection in response to angiotensin II. Hypertension. 2007;50(1): 189-196.

98. Mehranpour P, Wang SS, Blanco RR, et al. The C242T CYBA polymorphism as a major determinant of NADPH oxidase activity in patients with cardiovascular disease. Cardiovasc Hematol Agents Med Chem. 2009;7(3):251-259.

99. Moreno MU, San Jose G, Fortuno A, Beloqui O, Díez J, Zalba G. The C242T CYBA polymorphism of NADPH oxidase is associated with essential hypertension. J Hypertens. 2006;24(7):1299-1306.

100. Mittal M, Roth M, Konig P, et al. Hypoxia-dependent regulation of nonphagocytic NADPH oxidase subunit NOX4 in the pulmonary vasculature. Circ Res. 2007;101(3):258-267.

101. Selemidis S, Sobey CG, Wingler K, Schmidt HH, Drummond GR. NADPH oxidases in the vasculature: molecular features, roles in disease and pharmacological inhibition. Pharmacol Ther. 2008;120(3): 254-291.

102. Jung O, Schreiber JG, Geiger H, Pedrazzini T, Busse R, Brandes RP. gp91phox-containing NADPH oxidase mediates endothelial dysfunction in renovascular hypertension. Circulation. 2004;109(14):1795-1801. 
103. Rey FE, Cifuentes ME, Kiarash A, Quinn MT, Pagano PJ. Novel competitive inhibitor of NAD(P)H oxidase assembly attenuates vascular $\mathrm{O}(2)(-)$ and systolic blood pressure in mice. Circ Res. 2001;89(5):408-414.

104. Brennan AM, Suh SW, Won SJ, et al. NADPH oxidase is the primary source of superoxide induced by NMDA receptor activation. Nat Neurosci. 2009;12(7):857-863.

105. Park L, Zhou P, Pitstick R, et al. Nox2-derived radicals contribute to neurovascular and behavioral dysfunction in mice overexpressing the amyloid precursor protein. Proc Natl Acad Sci U S A. 2008;105(4): 1347-1352.

106. Banfi B, Molnar G, Maturana A, et al. A Ca(2+)-activated NADPH oxidase in testis, spleen, and lymph nodes. J Biol Chem. 2001;276(40): 37594-37601.

107. Ushio-Fukai M. Compartmentalization of redox signaling through NADPH oxidase-derived ROS. Antioxid Redox Signal. 2009;11(6): 1289-1299.

108. Hilenski LL, Clempus RE, Quinn MT, Lambeth JD, Griendling KK. Distinct subcellular localizations of Nox 1 and Nox 4 in vascular smooth muscle cells. Arterioscler Thromb Vasc Biol. 2004;24(4):677-683.

109. Ushio-Fukai M, Zafari AM, Fukui T, Ishizaka N, Griendling KK. p22phox is a critical component of the superoxide-generating NADH/NADPH oxidase system and regulates angiotensin II-induced hypertrophy in vascular smooth muscle cells. J Biol Chem. 1996;271(38):23317-23321

110. Zafari AM, Ushio-Fukai M, Akers M, et al. Role of NADH/NADPH oxidase-derived $\mathrm{H} 2 \mathrm{O} 2$ in angiotensin II-induced vascular hypertrophy. Hypertension. 1998;32(3):488-495.

111. Callera GE, Montezano AC, Yogi A, Tostes RC, Touyz RM. Vascular signaling through cholesterol-rich domains: implications in hypertension. Curr Opin Nephrol Hypertens. 2007;16(2):90-104.

112. Miller FJ Jr, Chu X, Stanic B, et al. A differential role for endocytosis in receptor-mediated activation of Nox1. Antioxid Redox Signal. 2010;12(5):583-593

113. Miller FJ Jr, Filali M, Huss GJ, et al. Cytokine activation of nuclear factor kappa B in vascular smooth muscle cells requires signaling endosomes containing Nox1 and ClC-3. Circ Res. 2007;101(7): 663-671.

114. Zhang AY, Yi F, Zhang G, Gulbins E, Li PL. Lipid raft clustering and redox signaling platform formation in coronary arterial endothelial cells. Hypertension. 2006;47(1):74-80.

115. Yang B, Rizzo V. TNF-alpha potentiates protein-tyrosine nitration through activation of NADPH oxidase and eNOS localized in membrane rafts and caveolae of bovine aortic endothelial cells. $A m \mathrm{~J}$ Physiol Heart Circ Physiol. 2007;292(2):H954-H962.

116. Li PL, Gulbins E. Lipid rafts and redox signaling. Antioxid Redox Signal. 2007;9(9):1411-1415.

117. Chen KD, Li YS, Kim M, et al. Mechanotransduction in response to shear stress. Roles of receptor tyrosine kinases, integrins, and Shc. J Biol Chem. 1999;274(26):18393-18400.

118. Ishida T, Peterson TE, Kovach NL, Berk BC. MAP kinase activation by flow in endothelial cells. Role of beta 1 integrins and tyrosine kinases. Circ Res. 1996;79(2):310-316.

119. Jalali S, Li YS, Sotoudeh M, et al. Shear stress activates p60 src-RasMAPK signaling pathways in vascular endothelial cells. Arterioscler Thromb Vasc Biol. 1998;18(2):227-234.

120. Sieg DJ, Hauck CR, Ilic D, et al. FAK integrates growth-factor and integrin signals to promote cell migration. Nat Cell Biol. 2000;2(5): 249-256.

121. Tzima E, del Pozo MA, Shattil SJ, Chien S, Schwartz MA. Activation of integrins in endothelial cells by fluid shear stress mediates Rho-dependent cytoskeletal alignment. EMBO J. 2001;20(17): 4639-4647.

122. Chiarugi P. From anchorage dependent proliferation to survival: lessons from redox signalling. IUBMB Life. 2008;60(5):301-307.

123. Chiarugi P, Cirri P. Redox regulation of protein tyrosine phosphatases during receptor tyrosine kinase signal transduction. Trends Biochem Sci. 2003;28(9):509-514.
124. Finkel T. Signal transduction by reactive oxygen species. J Cell Biol. 2011;194(1):7-15.

125. Lee SR, Kwon KS, Kim SR, Rhee SG. Reversible inactivation of protein-tyrosine phosphatase $1 \mathrm{~B}$ in A431 cells stimulated with epidermal growth factor. J Biol Chem. 1998;273(25):15366-15372.

126. Meng TC, Fukada T, Tonks NK. Reversible oxidation and inactivation of protein tyrosine phosphatases in vivo. Mol Cell. 2002;9(2):387-399.

127. Dejana E, Corada M, Lampugnani MG. Endothelial cell-to-cell junctions. FASEB J. 1995;9(10):910-918.

128. Esser S, Wolburg K, Wolburg H, Breier G, Kurzchalia T, Risau W. Vascular endothelial growth factor induces endothelial fenestrations in vitro. J Cell Biol. 1998;140(4):947-959.

129. Nawroth R, Poell G, Ranft A, et al. VE-PTP and VE-cadherin ectodomains interact to facilitate regulation of phosphorylation and cell contacts. EMBO J. 2002;21(18):4885-4895.

130. Wright TJ, Leach L, Shaw PE, Jones P. Dynamics of vascular endothelial-cadherin and beta-catenin localization by vascular endothelial growth factor-induced angiogenesis in human umbilical vein cells. Exp Cell Res. 2002;280(2):159-168.

131. Lin MT, Yen ML, Lin CY, Kuo ML. Inhibition of vascular endothelial growth factor-induced angiogenesis by resveratrol through interruption of Src-dependent vascular endothelial cadherin tyrosine phosphorylation. Mol Pharmacol. 2003;64(5):1029-1036.

132. van Wetering S, van Buul JD, Quik S, et al. Reactive oxygen species mediate Rac-induced loss of cell-cell adhesion in primary human endothelial cells. J Cell Sci. 2002;115(Pt 9):1837-1846.

133. Nwariaku FE, Liu Z, Zhu X, et al. NADPH oxidase mediates vascular endothelial cadherin phosphorylation and endothelial dysfunction. Blood. 2004;104(10):3214-3220.

134. Yamaoka-Tojo M, Tojo T, Kim HW, et al. IQGAP1 mediates VE-cadherin-based cell-cell contacts and VEGF signaling at adherence junctions linked to angiogenesis. Arterioscler Thromb Vasc Biol. 2006;26(9):1991-1997.

135. Yamaoka-Tojo M, Ushio-Fukai M, Hilenski L, et al. IQGAP1, a novel vascular endothelial growth factor receptor binding protein, is involved in reactive oxygen species-dependent endothelial migration and proliferation. Circ Res. 2004;95(3):276-283.

136. Allingham MJ, van Buul JD, Burridge K. ICAM-1-mediated, Src- and Pyk2-dependent vascular endothelial cadherin tyrosine phosphorylation is required for leukocyte transendothelial migration. J Immunol. 2007;179(6):4053-4064.

137. Tang FY, Nguyen N, Meydani M. Green tea catechins inhibit VEGFinduced angiogenesis in vitro through suppression of VE-cadherin phosphorylation and inactivation of Akt molecule. Int $J$ Cancer. 2003;106(6):871-878.

138. Colavitti R, Pani G, Bedogni B, et al. Reactive oxygen species as downstream mediators of angiogenic signaling by vascular endothelial growth factor receptor-2/KDR. J Biol Chem. 2002;277(5): 3101-3108.

139. Ikeda S, Ushio-Fukai M, Zuo L, et al. Novel role of ARF6 in vascular endothelial growth factor-induced signaling and angiogenesis. Circ Res. 2005;96(4):467-475.

140. Ushio-Fukai M, Tang Y, Fukai T, et al. Novel role of gp91(phox)containing $\mathrm{NAD}(\mathrm{P}) \mathrm{H}$ oxidase in vascular endothelial growth factor-induced signaling and angiogenesis. Circ Res. 2002;91(12): 1160-1167.

141. Wu RF, Gu Y, Xu YC, Nwariaku FE, Terada LS. Vascular endothelial growth factor causes translocation of $\mathrm{p} 47 \mathrm{phox}$ to membrane ruffles through WAVE1. J Biol Chem. 2003;278(38):36830-36840.

142. Wu RF, Xu YC, Ma Z, Nwariaku FE, Sarosi GA Jr, Terada LS. Subcellular targeting of oxidants during endothelial cell migration. J Cell Biol. 2005;171(5):893-904.

143. Ikeda S, Yamaoka-Tojo M, Hilenski L, et al. IQGAP1 regulates reactive oxygen species-dependent endothelial cell migration through interacting with Nox2. Arterioscler Thromb Vasc Biol. 2005;25(11): 2295-2300. 
144. Moldovan L, Moldovan NI, Sohn RH, Parikh SA, GoldschmidtClermont PJ. Redox changes of cultured endothelial cells and actin dynamics. Circ Res. 2000;86(5):549-557.

145. Wientjes FB, Reeves EP, Soskic V, Furthmayr H, Segal AW. The NADPH oxidase components p47(phox) and p40(phox) bind to moesin through their PX domain. Biochem Biophys Res Commun. 2001;289(2):382-388.

146. Briggs MW, Sacks DB. IQGAP proteins are integral components of cytoskeletal regulation. EMBO Rep. 2003;4(6):571-574.

147. Mateer SC, Wang N, Bloom GS. IQGAPs: integrators of the cytoskeleton, cell adhesion machinery, and signaling networks. Cell Motil Cytoskeleton. 2003;55(3):147-155

148. Li JM, Shah AM. Intracellular localization and preassembly of the NADPH oxidase complex in cultured endothelial cells. J Biol Chem. 2002;277(22):19952-19960.

149. Van Buul JD, Fernandez-Borja M, Anthony EC, Hordijk PL. Expression and localization of NOX2 and NOX4 in primary human endothelial cells. Antioxid Redox Signal. 2005;7(3-4):308-317.

150. Chen K, Kirber MT, Xiao H, Yang Y, Keaney JF Jr. Regulation of ROS signal transduction by NADPH oxidase 4 localization. $J$ Cell Biol. 2008;181(7):1129-1139.

151. Li Q, Harraz MM, Zhou W, et al. Nox2 and Rac1 regulate H2O2dependent recruitment of TRAF6 to endosomal interleukin-1 receptor complexes. Mol Cell Biol. 2006;26(1):140-154.

152. Li Q, Zhang Y, Marden JJ, Banfi B, Engelhardt JF. Endosomal NADPH oxidase regulates c-Src activation following hypoxia/reoxygenation injury. Biochem J. 2008;411(3):531-541.

153. Abate C, Patel L, Rauscher FJ III, Curran T. Redox regulation of fos and jun DNA-binding activity in vitro. Science. 1990;249(4973): 1157-1161.

154. Allen RG, Tresini M. Oxidative stress and gene regulation. Free Radic Biol Med. 2000;28(3):463-499.

155. Bloom D, Dhakshinamoorthy S, Jaiswal AK. Site-directed mutagenesis of cysteine to serine in the DNA binding region of $\mathrm{Nrf} 2$ decreases its capacity to upregulate antioxidant response element-mediated expression and antioxidant induction of NAD(P)H:quinone oxidoreductase1 gene. Oncogene. 2002;21(14):2191-2200.

156. Bodwell JE, Holbrook NJ, Munck A. Sulfhydryl-modifying reagents reversibly inhibit binding of glucocorticoid-receptor complexes to DNA-cellulose. Biochemistry. 1984;23(7):1392-1398.

157. Galter D, Mihm S, Droge W. Distinct effects of glutathione disulphide on the nuclear transcription factor kappa B and the activator protein-1. Eur J Biochem. 1994;221(2):639-648.

158. Hainaut P, Milner J. Redox modulation of p53 conformation and sequence-specific DNA binding in vitro. Cancer Res. 1993;53(19): 4469-4473.

159. Hansen JM, Go YM, Jones DP. Nuclear and mitochondrial compartmentation of oxidative stress and redox signaling. Annu Rev Pharmacol Toxicol. 2006;46:215-234.

160. Kuroda J, Nakagawa K, Yamasaki T, et al. The superoxide-producing NAD(P)H oxidase Nox4 in the nucleus of human vascular endothelial cells. Genes Cells. 2005;10(12):1139-1151.

161. Sorescu D, Weiss D, Lassegue B, et al. Superoxide production and expression of nox family proteins in human atherosclerosis. Circulation. 2002;105(12):1429-1435.

162. Richard D, Wolf C, Barbe U, Kefi K, Bausero P, Visioli F. Docosahexaenoic acid down-regulates endothelial Nox 4 through a sPLA2 signalling pathway. Biochem Biophys Res Commun. 2009;389(3):516-522.

163. Spanier G, Xu H, Xia N, et al. Resveratrol reduces endothelial oxidative stress by modulating the gene expression of superoxide dismutase 1 (SOD1), glutathione peroxidase 1 (GPx1) and NADPH oxidase subunit (Nox4). J Physiol Pharmacol. 2009;60 Suppl 4111-4116.

164. Muzaffar S, Jeremy JY, Sparatore A, et al. Resveratrol reduces endothelial oxidative stress by modulating the gene expression of superoxide dismutase 1. Br J Pharmacol. 2008;155(7): 984-994.
165. Shukla N, Rossoni G, Hotston M, et al. Effect of hydrogen sulphidedonating sildenafil (ACS6) on erectile function and oxidative stress in rabbit isolated corpus cavernosum and in hypertensive rats. $B J U$ Int. 2009;103(11):1522-1529.

166. Xu J, Li N, Dai DZ, Yu F, Dai Y. The endothelin receptor antagonist CPU0213 is more effective than aminoguanidine to attenuate isoproterenolinduced vascular abnormality by suppressing overexpression of NADPH oxidase [correction of oxidas], ETA, ETB, and MMP9 in the vasculature. J Cardiovasc Pharmacol. 2008;52(1):42-48.

167. Gomez-Guzman M, Jimenez R, Sanchez M, et al. Epicatechin lowers blood pressure, restores endothelial function, and decreases oxidative stress and endothelin-1 and NADPH oxidase activity in DOCA-salt hypertension. Free Radic Biol Med. 2012;52(1):70-79.

168. Zhang HB, Wen JK, Zhang J, et al. Flavonoids from Inula britannica reduces oxidative stress through inhibiting expression and phosphorylation of p47(phox) in VSMCs. Pharm Biol. 2011;49(8): 815-820.

169. Wang P, Wu X, Bao Y, et al. Tanshinone IIA prevents cardiac remodeling through attenuating NAD (P)H oxidase-derived reactive oxygen species production in hypertensive rats. Pharmazie. 2011;66(7):517-524.

170. Zhang S, Chen B, Wu W, Bao L, Qi R. Ginkgolide B reduces inflammatory protein expression in oxidized low-density lipoproteinstimulated human vascular endothelial cells. J Cardiovasc Pharmacol. 2011;57(6):721-727.

171. Bao MH, Dai W, Li YJ, Hu CP. Rutaecarpine prevents hypoxiareoxygenation-induced myocardial cell apoptosis via inhibition of NADPH oxidases. Can J Physiol Pharmacol. 2011;89(3): 177-186.

172. Bai YP, Hu CP, Chen MF, et al. Inhibitory effect of reinioside $\mathrm{C}$ on monocyte-endothelial cell adhesion induced by oxidized lowdensity lipoprotein via inhibiting NADPH oxidase/ROS/NF-kappaB pathway. Naunyn Schmiedebergs Arch Pharmacol. 2009;380(5): 399-406.

173. Romero M, Jimenez R, Sanchez M, et al. Quercetin inhibits vascular superoxide production induced by endothelin-1: role of NADPH oxidase, uncoupled eNOS and PKC. Atherosclerosis. 2009;202(1):58-67.

174. Manea A, Manea SA, Gafencu AV, Raicu M, Simionescu M. AP-1dependent transcriptional regulation of NADPH oxidase in human aortic smooth muscle cells: role of p22phox subunit. Arterioscler Thromb Vasc Biol. 2008;28(5):878-885.

175. Li H, Hortmann M, Daiber A, et al. Cyclooxygenase 2-selective and nonselective nonsteroidal anti-inflammatory drugs induce oxidative stress by up-regulating vascular NADPH oxidases. J Pharmacol Exp Ther. 2008;326(3):745-753.

176. Guzik TJ, West NE, Black E, et al. Functional effect of the C242T polymorphism in the NAD $(\mathrm{P}) \mathrm{H}$ oxidase $\mathrm{p} 22$ phox gene on vascular superoxide production in atherosclerosis. Circulation. 2000;102(15): $1744-1747$.

177. Jaquet V, Scapozza L, Clark RA, Krause KH, Lambeth JD. Smallmolecule NOX inhibitors: ROS-generating NADPH oxidases as therapeutic targets. Antioxid Redox Signal. 2009;11(10): 2535-2552.

178. Streeter J, Thiel W, Brieger K, Miller FJ Jr. Opportunity Nox: the future of NADPH oxidases as therapeutic targets in cardiovascular disease. Cardiovasc Ther. 2013;31(3):125-137.

179. O’Donnell BV, Tew DG, Jones OT, England PJ. Studies on the inhibitory mechanism of iodonium compounds with special reference to neutrophil NADPH oxidase. Biochem J. 1993;290(Pt 1):41-49.

180. O’Donnell VB, Smith GC, Jones OT. Involvement of phenyl radicals in iodonium inhibition of flavoenzymes. Mol Pharmacol. 1994;46(4): 778-785.

181. Stolk J, Hiltermann TJ, Dijkman JH, Verhoeven AJ. Characteristics of the inhibition of NADPH oxidase activation in neutrophils by apocynin, a methoxy-substituted catechol. Am J Respir Cell Mol Biol. 1994;11(1):95-102. 
182. Ghosh M, Wang HD, McNeill JR. Role of oxidative stress and nitric oxide in regulation of spontaneous tone in aorta of DOCA-salt hypertensive rats. Br J Pharmacol. 2004;141(4):562-573.

183. Engels F, Renirie BF, Hart BA, Labadie RP, Nijkamp FP. Effects of apocynin, a drug isolated from the roots of Picrorhiza kurroa, on arachidonic acid metabolism. FEBS Lett. 1992;305(3):254-256.

184. Lapperre TS, Jimenez LA, Antonicelli F, et al. Apocynin increases glutathione synthesis and activates AP-1 in alveolar epithelial cells. FEBS Lett. 1999;443(2):235-239.

185. Heumuller S, Wind S, Barbosa-Sicard E, et al. Apocynin is not an inhibitor of vascular NADPH oxidases but an antioxidant. Hypertension. 2008;51(2):211-217.

186. Kutsumi H, Kawai K, Johnston RB Jr, Rokutan K. Evidence for participation of vicinal dithiols in the activation sequence of the respiratory burst of human neutrophils. Blood. 1995;85(9): 2559-2569.

187. Hamilton CA, Brosnan MJ, Al-Benna S, Berg G, Dominiczak AF. $\mathrm{NAD}(\mathrm{P}) \mathrm{H}$ oxidase inhibition improves endothelial function in rat and human blood vessels. Hypertension. 2002;40(5):755-762.

188. Li YL, Gao L, Zucker IH, Schultz HD. NADPH oxidase-derived superoxide anion mediates angiotensin II-enhanced carotid body chemoreceptor sensitivity in heart failure rabbits. Cardiovasc Res. 2007;75(3):546-554.

189. Fanelus I, Desrosiers RR. Reactive oxygen species generated by thiol-modifying phenylarsine oxide stimulate the expression of protein L-isoaspartyl methyltransferase. Biochem Biophys Res Commun. 2008;371(2):203-208.

190. Tsunawaki S, Yoshida LS, Nishida S, Kobayashi T, Shimoyama T. Fungal metabolite gliotoxin inhibits assembly of the human respiratory burst NADPH oxidase. Infect Immun. 2004;72(6):3373-3382.

191. Nishida S, Yoshida LS, Shimoyama T, Nunoi H, Kobayashi T, Tsunawaki S. Fungal metabolite gliotoxin targets flavocytochrome b558 in the activation of the human neutrophil NADPH oxidase. Infect Immun. 2005;73(1):235-244.

192. Diatchuk V, Lotan O, Koshkin V, Wikstroem P, Pick E. Inhibition of NADPH oxidase activation by 4-(2-aminoethyl)-benzenesulfonyl fluoride and related compounds. J Biol Chem. 1997;272(20):13292-13301.

193. Wind S, Beuerlein K, Eucker T, et al. Comparative pharmacology of chemically distinct NADPH oxidase inhibitors. Br J Pharmacol. 2010;161(4):885-898.

194. Stielow C, Catar RA, Muller G, et al. Novel Nox inhibitor of oxLDLinduced reactive oxygen species formation in human endothelial cells. Biochem Biophys Res Commun. 2006;344(1):200-205.

195. Tsai MH, Jiang MJ. Reactive oxygen species are involved in regulating alpha1-adrenoceptor-activated vascular smooth muscle contraction. J Biomed Sci. 2010;17:67.

196. Laleu B, Gaggini F, Orchard M, et al. First in class, potent, and orally bioavailable NADPH oxidase isoform 4 (Nox4) inhibitors for the treatment of idiopathic pulmonary fibrosis. J Med Chem. 2010;53(21): $7715-7730$

197. Green DE, Murphy TC, Kang BY, et al. The Nox4 inhibitor GKT137831 attenuates hypoxia-induced pulmonary vascular cell proliferation. Am J Respir Cell Mol Biol. 2012;47(5):718-726.

198. Cayatte AJ, Rupin A, Oliver-Krasinski J, et al. S17834, a new inhibitor of cell adhesion and atherosclerosis that targets NADPH oxidase. Arterioscler Thromb Vasc Biol. 2001;21(10):1577-1584.

199. Jaulmes A, Sansilvestri-Morel P, Rolland-Valognes G, et al. Nox4 mediates the expression of plasminogen activator inhibitor-1 via p38 MAPK pathway in cultured human endothelial cells. Thromb Res. 2009;124(4):439-446.

200. Zang M, Xu S, Maitland-Toolan KA, et al. Polyphenols stimulate AMP-activated protein kinase, lower lipids, and inhibit accelerated atherosclerosis in diabetic LDL receptor-deficient mice. Diabetes. 2006;55(8):2180-2191.

201. Ding Y, Chen ZJ, Liu S, Che D, Vetter M, Chang CH. Inhibition of Nox-4 activity by plumbagin, a plant-derived bioactive naphthoquinone. J Pharm Pharmacol. 2005;57(1):111-116.
202. Sharma I, Gusain D, Dixit VP. Hypolipidaemic and antiatherosclerotic effects of plumbagin in rabbits. Indian J Physiol Pharmacol. 1991;35(1):10-14.

203. Gianni D, Taulet N, Zhang H, et al. A novel and specific NADPH oxidase-1 (Nox1) small-molecule inhibitor blocks the formation of functional invadopodia in human colon cancer cells. ACS Chem Biol. 2010;5(10):981-993.

204. Bhandarkar SS, Jaconi M, Fried LE, et al. Fulvene-5 potently inhibits NADPH oxidase 4 and blocks the growth of endothelial tumors in mice. J Clin Invest. 2009;119(8):2359-2365.

205. El-Benna J, Dang PM, Perianin A. Towards specific NADPH oxidase inhibition by small synthetic peptides. Cell Mol Life Sci. 2012;69(14):2307-2314.

206. DeLeo FR, Nauseef WM, Jesaitis AJ, Burritt JB, Clark RA, Quinn MT. A domain of p47phox that interacts with human neutrophil flavocytochrome b558. J Biol Chem. 1995;270(44):26246-26251.

207. Csanyi G, Cifuentes-Pagano E, Al Ghouleh I, et al. Nox2 B-loop peptide, Nox2ds, specifically inhibits the NADPH oxidase Nox2. Free Radic Biol Med. 2011;51(6):1116-1125.

208. Shi J, Ross CR, Leto TL, Blecha F. PR-39, a proline-rich antibacterial peptide that inhibits phagocyte NADPH oxidase activity by binding to Src homology 3 domains of 47 phox. Proc Natl Acad Sci USA. 1996;93(12):6014-6018.

209. Al-Awwadi NA, Araiz C, Bornet A, et al. Extracts enriched in different polyphenolic families normalize increased cardiac NADPH oxidase expression while having differential effects on insulin resistance, hypertension, and cardiac hypertrophy in high-fructose-fed rats. J Agric Food Chem. 2005;53(1):151-157.

210. Jimenez R, Lopez-Sepulveda R, Kadmiri M, et al. Polyphenols restore endothelial function in DOCA-salt hypertension: role of endothelin-1 and NADPH oxidase. Free Radic Biol Med. 2007;43(3):462-473.

211. Badimon L, Vilahur G, Padro T. Nutraceuticals and atherosclerosis: human trials. Cardiovasc Ther. 2010;28(4):202-215.

212. Agouni A, Lagrue-Lak-Hal AH, Mostefai HA, et al. Red wine polyphenols prevent metabolic and cardiovascular alterations associated with obesity in Zucker fatty rats $(\mathrm{Fa} / \mathrm{Fa})$. PLoS One. 2009;4(5):e5557.

213. Lopez-Sepulveda R, Gomez-Guzman M, Zarzuelo MJ, et al. Red wine polyphenols prevent endothelial dysfunction induced by endothelin-1 in rat aorta: role of NADPH oxidase. Clin Sci (Lond). 2011;120(8):321-333

214. Dal-Ros S, Zoll J, Lang AL, et al. Chronic intake of red wine polyphenols by young rats prevents aging-induced endothelial dysfunction and decline in physical performance: role of NADPH oxidase. Biochem Biophys Res Commun. 2011;404(2):743-749.

215. Alvarez E, Rodino-Janeiro BK, Jerez M, Ucieda-Somoza R, Núñez MJ, González-Juanatey JR. Procyanidins from grape pomace are suitable inhibitors of human endothelial NADPH oxidase. $J$ Cell Biochem. 2012;113(4):1386-1396.

216. Orallo F, Alvarez E, Camina M, Leiro JM, Gómez E, Fernández P. The possible implication of trans-resveratrol in the cardioprotective effects of long-term moderate wine consumption. Mol Pharmacol. 2002;61(2):294-302.

217. Gomez-Guzman M, Jimenez R, Sanchez M, et al. Chronic (-)-epicatechin improves vascular oxidative and inflammatory status but not hypertension in chronic nitric oxide-deficient rats. Br J Nutr. 2011;106(9):1337-1348.

218. Hwang SY, Siow YL, Au-Yeung KK, House J. Folic acid supplementation inhibits NADPH oxidase-mediated superoxide anion production in the kidney. Am J Physiol Renal Physiol. 2011;300(1): F189-F198.

219. Wang JP, Hsu MF, Raung SL, et al. Inhibition by magnolol of formylmethionyl-leucyl-phenyl alanine-induced respiratory burst in rat neutrophils. J Pharm Pharmacol. 1999;51(3):285-294.

220. Chuang DY, Chan MH, Zong Y, et al. Magnolia polyphenols attenuate oxidative and inflammatory responses in neurons and microglial cells. J Neuroinflammation. 2013;10:15. 
221. Tsai SK, Huang CH, Huang SS, Hung LM, Hong CY. Antiarrhythmic effect of magnolol and honokiol during acute phase of coronary occlusion in anesthetized rats: influence of L-NAME and aspirin. Pharmacology. 1999;59(5):227-233.

222. Tsai SK, Huang SS, Hong CY. Myocardial protective effect of honokiol: an active component in Magnolia officinalis. Planta Med. 1996;62(6):503-506.

223. Sheu ML, Chiang CK, Tsai KS, et al. Inhibition of NADPH oxidaserelated oxidative stress-triggered signaling by honokiol suppresses high glucose-induced human endothelial cell apoptosis. Free Radic Biol Med. 2008;44(12):2043-2050.

224. Li P, Yang Y, Liu M. Xuezhikang, extract of red yeast rice, inhibited tissue factor and hypercoagulable state through suppressing nicotinamide adenine dinucleotide phosphate oxidase and extracellular signal-regulated kinase activation. $J$ Cardiovasc Pharmacol. 2011; 58(3):307-318

225. Kim J, Kim KM, Kim CS, et al. Puerarin inhibits the retinal pericyte apoptosis induced by advanced glycation end products in vitro and in vivo by inhibiting NADPH oxidase-related oxidative stress. Free Radic Biol Med. 2012;53(2):357-365.

226. Wu F, Han M, Wilson JX. Tripterine prevents endothelial barrier dysfunction by inhibiting endogenous peroxynitrite formation. $\mathrm{Br} J$ Pharmacol. 2009;157(6):1014-1023.

227. Jaquet V, Marcoux J, Forest E, et al. NADPH oxidase (NOX) isoforms are inhibited by celastrol with a dual mode of action. Br J Pharmacol. 2011;164(2b):507-520.

228. Borbely G, Szabadkai I, Horvath Z, et al. Small-molecule inhibitors of NADPH oxidase 4. J Med Chem. 2010;53(18):6758-6762.

229. Karagulova G, Yue Y, Moreyra A, Boutjdir M, Korichneva I. Protective role of intracellular zinc in myocardial ischemia/reperfusion is associated with preservation of protein kinase $\mathrm{C}$ isoforms. J Pharmacol Exp Ther. 2007;321(2):517-525.

230. Kasi V, Bodiga S, Kommuguri UN, Sankuru S, Bodiga VL. Zinc pyrithione salvages reperfusion injury by inhibiting NADPH oxidase activation in cardiomyocytes. Biochem Biophys Res Commun. 2011;410(2):270-275.

231. Smith SM, Min J, Ganesh T, et al. Ebselen and congeners inhibit NADPH oxidase 2-dependent superoxide generation by interrupting the binding of regulatory subunits. Chem Biol. 2012;19(6): $752-763$.

232. [No authors listed]. Ebselen could be used as anti-inflammatory Nox inhibitor. Future Med Chem. 2012;4(12):1533-1535.

233. Wang Q, Zhou H, Gao H, et al. Naloxone inhibits immune cell function by suppressing superoxide production through a direct interaction with gp91phox subunit of NADPH oxidase. J Neuroinflammation. 2012;9:32.

234. Zhang H, Schmeisser A, Garlichs CD, et al. Angiotensin II-induced superoxide anion generation in human vascular endothelial cells: role of membrane-bound NADH-/NADPH-oxidases. Cardiovasc Res. 1999;44(1):215-222.

235. Griendling KK, Minieri CA, Ollerenshaw JD, Alexander RW. Angiotensin II stimulates NADH and NADPH oxidase activity in cultured vascular smooth muscle cells. Circ Res. 1994;74(6): $1141-1148$.

236. Miguel-Carrasco JL, Zambrano S, Blanca AJ, Mate A, Vázquez CM. Captopril reduces cardiac inflammatory markers in spontaneously hypertensive rats by inactivation of NF-kB. J Inflamm (Lond). 2010;7:21.

237. Liu XP, Pang YJ, Zhu WW, et al. Benazepril, an angiotensinconverting enzyme inhibitor, alleviates renal injury in spontaneously hypertensive rats by inhibiting advanced glycation end-productmediated pathways. Clin Exp Pharmacol Physiol. 2009;36(3): 287-296.

238. Otto A, Fontaine J, Berkenboom G. Ramipril treatment protects against nitrate-induced oxidative stress in eNOS-/- mice: an implication of the NADPH oxidase pathway. J Cardiovasc Pharmacol. 2006;48(1):842-849.
239. Rueckschloss U, Quinn MT, Holtz J, Morawietz H. Dose-dependent regulation of $\mathrm{NAD}(\mathrm{P}) \mathrm{H}$ oxidase expression by angiotensin II in human endothelial cells: protective effect of angiotensin II type 1 receptor blockade in patients with coronary artery disease. Arterioscler Thromb Vasc Biol. 2002;22(11):1845-1851.

240. Berry C, Hamilton CA, Brosnan MJ, et al. Investigation into the sources of superoxide in human blood vessels: angiotensin II increases superoxide production in human internal mammary arteries. Circulation. 2000;101(18):2206-2212.

241. Poss J, Werner C, Lorenz D, Gensch C, Böhm M, Laufs U. The renin inhibitor aliskiren upregulates pro-angiogenic cells and reduces atherogenesis in mice. Basic Res Cardiol. 2010;105(6):725-735.

242. Whaley-Connell A, Habibi J, Rehmer N, et al. Renin inhibition and AT(1)R blockade improve metabolic signaling, oxidant stress and myocardial tissue remodeling. Metabolism. 2013;62(6): 861-872.

243. Favre J, Gao J, Zhang AD, et al. Coronary endothelial dysfunction after cardiomyocyte-specific mineralocorticoid receptor overexpression. Am J Physiol Heart Circ Physiol. 2011;300(6):H2035-H2043.

244. Shi G, Fu Y, Jiang W, et al. Activation of Src-ATF1 pathway is involved in upregulation of Nox1, a catalytic subunit of NADPH oxidase, by aldosterone. Endocr J. 2011;58(6):491-499.

245. Sartorio CL, Fraccarollo D, Galuppo P, et al. Mineralocorticoid receptor blockade improves vasomotor dysfunction and vascular oxidative stress early after myocardial infarction. Hypertension. 2007;50(5):919-925.

246. Anderson TJ, Meredith IT, Yeung AC, Frei B, Selwyn AP, Ganz P. The effect of cholesterol-lowering and antioxidant therapy on endothelium-dependent coronary vasomotion. $N$ Engl $J$ Med. 1995;332(8):488-493.

247. Wassmann S, Laufs U, Muller K, et al. Cellular antioxidant effects of atorvastatin in vitro and in vivo. Arterioscler Thromb Vasc Biol. 2002;22(2):300-305.

248. Rueckschloss U, Galle J, Holtz J, Zerkowski HR, Morawietz H. Induction of $\mathrm{NAD}(\mathrm{P}) \mathrm{H}$ oxidase by oxidized low-density lipoprotein in human endothelial cells: antioxidative potential of hydroxymethylglutaryl coenzyme A reductase inhibitor therapy. Circulation. 2001;104(15):1767-1772.

249. Vecchione C, Gentile MT, Aretini A, et al. A novel mechanism of action for statins against diabetes-induced oxidative stress. Diabetologia. 2007;50(4):874-880.

250. Martinez-Gonzalez J, Badimon L. Influence of statin use on endothelial function: from bench to clinics. Curr Pharm Des. 2007;13(17): 1771-1786.

251. Yagi S, Akaike M, Aihara K, et al. Endothelial nitric oxide synthaseindependent protective action of statin against angiotensin II-induced atrial remodeling via reduced oxidant injury. Hypertension. 2010;55(4):918-923.

252. Kwok JM, Ma CC, Ma S. Recent development in the effects of statins on cardiovascular disease through Rac1 and NADPH oxidase. Vascul Pharmacol. 2013;58(1-2):21-30.

253. Montezano AC, Burger D, Paravicini TM, et al. Nicotinamide adenine dinucleotide phosphate reduced oxidase 5 (Nox5) regulation by angiotensin II and endothelin-1 is mediated via calcium/calmodulindependent, rac-1-independent pathways in human endothelial cells. Circ Res. 2010;106(8):1363-1373.

254. Toba H, Shimizu T, Miki S, et al. Calcium [corrected] channel blockers reduce angiotensin II-induced superoxide generation and inhibit lectin-like oxidized low-density lipoprotein receptor-1 expression in endothelial cells. Hypertens Res. 2006;29(2):105-116.

255. Yoshii T, Iwai M, Li Z, et al. Regression of atherosclerosis by amlodipine via anti-inflammatory and anti-oxidative stress actions. Hypertens Res. 2006;29(6):457-466.

256. Yamamoto E, Kataoka K, Dong YF, et al. Benidipine, a dihydropyridine L-type/T-type calcium channel blocker, affords additive benefits for prevention of cardiorenal injury in hypertensive rats. $J$ Hypertens. 2010;28(6):1321-1329. 
257. Yao R, Cheng X, Liao YH, et al. Molecular mechanisms of felodipine suppressing atherosclerosis in high-cholesterol-diet apolipoprotein E-knockout mice. J Cardiovasc Pharmacol. 2008;51(2):188-195.

258. Frey RS, Rahman A, Kefer JC, Minshall RD, Malik AB. PKCzeta regulates TNF-alpha-induced activation of NADPH oxidase in endothelial cells. Circ Res. 2002;90(9):1012-1019.

259. Raad H, Paclet MH, Boussetta T, et al. Regulation of the phagocyte NADPH oxidase activity: phosphorylation of gp91phox/NOX2 by protein kinase $\mathrm{C}$ enhances its diaphorase activity and binding to Rac2, p67phox, and p47phox. FASEB J. 2009;23(4):1011-1022.

260. Jagnandan D, Church JE, Banfi B, Stuehr DJ, Marrero MB, Fulton DJ. Novel mechanism of activation of NADPH oxidase 5. Calcium sensitization via phosphorylation. J Biol Chem. 2007;282(9): 6494-6507.

261. Li JM, Fan LM, Christie MR, Shah AM. Acute tumor necrosis factor alpha signaling via NADPH oxidase in microvascular endothelial cells: role of $\mathrm{p} 47$ phox phosphorylation and binding to TRAF4. Mol Cell Biol. 2005;25(6):2320-2330.

262. Mollnau H, Wendt M, Szocs K, et al. Effects of angiotensin II infusion on the expression and function of $\mathrm{NAD}(\mathrm{P}) \mathrm{H}$ oxidase and components of nitric oxide/cGMP signaling. Circ Res. 2002;90(4):E58-E65.

263. O'Donnell RW, Johnson DK, Ziegler LM, et al. Endothelial NADPH oxidase: mechanism of activation by low-density lipoprotein. Endothelium. 2003;10(6):291-297.

264. Gutterman DD. Vascular dysfunction in hyperglycemia: is protein kinase C the culprit? Circ Res. 2002;90(1):5-7.

265. Fenyo IM, Florea IC, Raicu M, Manea A. Tyrphostin AG490 reduces NAPDH oxidase activity and expression in the aorta of hypercholesterolemic apolipoprotein E-deficient mice. Vascul Pharmacol. 2011;54(3-6):100-106.

266. Lu C, Su LY, Lee RM, Gao YJ. Superoxide anion mediates angiotensin II-induced potentiation of contractile response to sympathetic stimulation. Eur J Pharmacol. 2008;589(1-3):188-193.

267. Galan M, Kassan M, Choi SK, et al. A novel role for epidermal growth factor receptor tyrosine kinase and its downstream endoplasmic reticulum stress in cardiac damage and microvascular dysfunction in type 1 diabetes mellitus. Hypertension. 2012;60(1): 71-80.

268. Puca R, Nardinocchi L, Starace G, et al. Nox 1 is involved in p53 deacetylation and suppression of its transcriptional activity and apoptosis. Free Radic Biol Med. 2010;48(10):1338-1346.
269. Li L, Gao P, Zhang H, et al. SIRT1 inhibits angiotensin II-induced vascular smooth muscle cell hypertrophy. Acta Biochim Biophys Sin (Shanghai). 2011;43(2):103-109.

270. Zarzuelo MJ, Lopez-Sepulveda R, Sanchez M, et al. SIRT1 inhibits NADPH oxidase activation and protects endothelial function in the rat aorta: implications for vascular aging. Biochem Pharmacol. 2011;43(2):103-109.

271. Wang D, Luo P, Wang Y, et al. Glucagon-like peptide-1 protects against cardiac microvascular injury in diabetes via a cAMP/PKA/ Rho-dependent mechanism. Diabetes. 2013;62(5):1697-1708.

272. Shiraki A, Oyama J, Komoda H, et al. The glucagon-like peptide 1 analog liraglutide reduces TNF-alpha-induced oxidative stress and inflammation in endothelial cells. Atherosclerosis. 2012;221(2): 375-382.

273. El-Benna J, Dang PM, Gougerot-Pocidalo MA. Priming of the neutrophil NADPH oxidase activation: role of $\mathrm{p} 47 \mathrm{phox}$ phosphorylation and NOX2 mobilization to the plasma membrane. Semin Immunopathol. 2008;30(3):279-289.

274. Banfi B, Clark RA, Steger K, Krause KH. Two novel proteins activate superoxide generation by the NADPH oxidase NOX1. J Biol Chem. 2003;278(6):3510-3513.

275. Bokoch GM, Diebold B, Kim JS, Gianni D. Emerging evidence for the importance of phosphorylation in the regulation of NADPH oxidases. Antioxid Redox Signal. 2009;11(10):2429-2441.

276. Yamamoto E, Kataoka K, Dong YF, et al. Calcium channel blockers, more than diuretics, enhance vascular protective effects of angiotensin receptor blockers in salt-loaded hypertensive rats. PLoS One. 2012;7(6):e39162.

277. Moreland JG, Davis AP, Bailey G, Nauseef WM, Lamb FS. Anion channels, including $\mathrm{ClC}-3$, are required for normal neutrophil oxidative function, phagocytosis, and transendothelial migration. J Biol Chem. 2006;281(18):12277-12288.

278. Lamb FS, Moreland JG, Miller FJ Jr. Electrophysiology of reactive oxygen production in signaling endosomes. Antioxid Redox Signal. 2009;11(6):1335-1347.

279. Schroder K, Zhang M, Benkhoff S, et al. Nox4 is a protective reactive oxygen species generating vascular NADPH oxidase. Circ Res. 2012;110(9):1217-1225.

280. Ray R, Murdoch CE, Wang M, et al. Endothelial Nox4 NADPH oxidase enhances vasodilatation and reduces blood pressure in vivo. Arterioscler Thromb Vasc Biol. 2011;31(6):1368-1376.
Vascular Health and Risk Management

\section{Publish your work in this journal}

Vascular Health and Risk Management is an international, peerreviewed journal of therapeutics and risk management, focusing on concise rapid reporting of clinical studies on the processes involved in the maintenance of vascular health; the monitoring, prevention and treatment of vascular disease and its sequelae; and the involvement of

\section{Dovepress}

metabolic disorders, particularly diabetes. This journal is indexed on PubMed Central and MedLine. The manuscript management system is completely online and includes a very quick and fair peer-review system, which is all easy to use. Visit http://www.dovepress.com/ testimonials.php to read real quotes from published authors. 